University of San Diego

Digital USD

2014-12-01

\title{
Relationship between Age and Pre-End Stage Renal Disease Care in Elderly Hemodialysis Patients
}

Rubette Harford PhD, MSN, RN

University of San Diego

Follow this and additional works at: https://digital.sandiego.edu/dissertations

Part of the Nursing Commons

\section{Digital USD Citation}

Harford, Rubette PhD, MSN, RN, "Relationship between Age and Pre-End Stage Renal Disease Care in Elderly Hemodialysis Patients" (2014). Dissertations. 468.

https://digital.sandiego.edu/dissertations/468

This Dissertation: Open Access is brought to you for free and open access by the Theses and Dissertations at Digital USD. It has been accepted for inclusion in Dissertations by an authorized administrator of Digital USD. For more information, please contact digital@sandiego.edu. 


\title{
UNIVERSITY OF SAN DIEGO \\ Hahn School of Nursing and Health Science \\ DOCTOR OF PHILOSOPHY IN NURSING
}
Relationship between Age and Pre-End Stage Renal Disease Care in Elderly Hemodialysis Patients

By

Rubette Harford, MSN, RN

A dissertation presented to the

FACULTY OF THE HAHN SCHOOL OF NURSING AND HEALTH SCIENCE UNIVERSITY OF SAN DIEGO

\author{
In partial fulfillment of the requirements for the degree \\ DOCTOR OF PHILOSOPHY IN NURSING
}

December 2014

\section{DISSERTATION COMMITTEE}

Mary Jo Clark, PhD, RN, Chairperson

Jane Georges, $\mathrm{PhD}, \mathrm{RN}$

Keith Charles Norris, $\mathrm{PhD}, \mathrm{MD}$ 


\begin{abstract}
Purpose: The primary purpose of this dissertation was to examine the relationship between age and receipt of three components of pre-end stage renal disease care prior to first initiation of hemodialysis, and to explore the implications of differences in interpretation of funding policies for dialysis services in Puerto Rico and the U.S. mainland.
\end{abstract}

Background: The growing burden of chronic kidney disease (CKD) is a national public health concern, particularly within the aged population. It is estimated that more than 25 million Americans are living with some level of kidney disease, with an increasing prevalence noted with increasing age (Coresh et al., 2007). Although the Center for Medicare and Medicaid Services (CMS) is the primary payer for CKD and ESRD services, differences in reimbursement policy interpretation between the U.S. mainland and Puerto Rico result in additional burdens for those served. Pre-end stage renal disease (ESRD) clinical care can improve outcomes for maintenance hemodialysis patients particularly within the elder population.

Methods: Data on the extent of pre-ESRD care by age were derived from the U.S. Renal Disease Data System for all patients started on dialysis from 2005 to 2010. Study variables included: (a) receipt of nephrology care 12 months prior to starting dialysis, (b) receipt of dietitian care at any time prior to starting dialysis, and (c) use of AVF at first dialysis. Data for the policy analysis was derived from CMS documents and interviews with stakeholders and regulatory agencies. 
Results: Less than $2 \%$ of MHD patients received all three pre-ESRD care elements, and $63.3 \%$ received none of the three elements of care. The mean number of pre-ESRD care elements received by the oldest group ( $\geq 80$ years) did not differ from the youngest group ( $\leq 55$ years), but was less than the 55-66 and 67-79 years groups. The policy analysis revealed regional variations in the interpretation of the coordination of ESRD benefits between the Territory of Puerto Rico and the national health system.

Implications: Major efforts are needed to ensure comprehensive pre-ESRD care for all patients with chronic kidney disease as well as a harmonizing of ESRD coordination of benefits for dialysis patients. 


\section{Dedication}

I would like to dedicate this dissertation to first and foremost my husband, Dr. Robert Harford and my family. Thank you, Robert, for being at my side through the countless long nights of study and giving me the encouragement to keep moving forward and not to look back. As you would always say, "Keep on moving. Never look back but always keep forward and don't be afraid. To my little girls: Mercedes who would take the time to read my papers and Ling- Ling who was always ready to bring mommy her coffee and tea. Mom and Dad, thank you for your love and prayers. To all my brothers, sisters and my twins, Rita Jo and Steven, thank you for your patience and caring. This paper goes to all of my family. 


\section{Acknowledgements}

This has been a long spiritual journey. I have many people whom I wish to acknowledge for you have contributed to the footsteps guiding me through the winding passage.

I would like to thank the entire faculty and staff at the University of San Diego Hahn School of Nursing and Health Science for the ongoing support, words of wisdom, and staff shared experiences. To my dissertation committee members, no words can express my gratitude and deep appreciation for your support and faith in my ability to succeed. Dr. Clark my faculty chairperson, you have been the pillar to my dissertation and professional success. When everything seemed to be falling apart and I was so lost, you always knew what to say to keep me going. You always had a way of putting things in perspective... and you were always right. I am very blessed to have had you as my chair. Dr. Georges, the many stories and experiences you shared during your $\mathrm{PhD}$ journey I will always remember. Thank you for recommending Dr. Clark as my chairperson and agreeing to be on my committee. I will always remember you for that. To Dr. Keith Norris, my long-time friend and role model, thank you for being there from the beginning to end. 
Dr. Guofen Yan, thank you for the biostatistical expertise you brought to the study. Your gift in teaching statistical analysis was great. Your approach to teaching $\mathrm{PhD}$ nursing students on the different ways of understanding logistic regression is truly a gift. Thank you for volunteering to work with the committee. Dr. Randall Maxey, my life-long mentor. Thank you for always being at my side.

While at USD, I acquired life-long relationships that will forever be a part of my life. My two classmates, Gloria Nwagwu and Kholoud Khalil, to whom I refer as the sisters, thank you for caring and being there through thick and thin. I love you both! 


\section{Table of Contents}

\section{Page}

Dedication

Acknowledgements $\quad$ ii

Chapter 1 Introduction 1

Chapter 2 Manuscript 1: Relationship between Age and Timely Placement of

Vascular Access in Incident Hemodialysis Patients 9

$\begin{array}{ll}\text { Copyright Permission } & 28\end{array}$

Chapter 3 Manuscript 2: Relationship between Age and Pre-End Stage Renal Disease

Care in Hemodialysis Patients

Chapter 4 Manuscript 3: Regional Variations in the Interpretation of the ESRD

30-Month Coordination Period

$\begin{array}{ll}\text { Chapter } 5 \text { Summary and Discussion } & 66\end{array}$

$\begin{array}{ll}\text { Appendix A Institutional Review Board Approval } & 78\end{array}$ 


\section{Chapter 1}

\section{Dissertation Introduction}

The growing burden of chronic kidney disease (CKD) is a national public health concern, particularly within the aged population. It is estimated that more than 25 million Americans are living with some level of kidney disease, with an increasing prevalence noted with increasing age (Coresh et al., 2007). Two key factors contributing to the increasing national prevalence of $\mathrm{CKD}$ are an aging population and the increasing prevalence of the leading CKD risk factors, diabetes and hypertension (Erdem, Prada, \& Haffer, 2013). People aged $\geq 65$ years comprise the fastest growing segment of the kidney failure population (Drawz, Babineau, \& Rahman, 2012; United States Renal Data System [USRDS], 2013a). Both diabetes- and hypertension-related kidney diseases are more common with increasing age (Yan et al., 2013). Diabetes now accounts for an estimated $45 \%$ of new cases of kidney failure and hypertension for an additional $30 \%$ (USRDS, 2013b). The implication of increased numbers of older persons and increased rates of $\mathrm{CKD}$ risk factors is a greater number of persons developing end-stage renal disease (ESRD), thereby creating a substantial burden for the national health care system. Renal replacement therapy with dialysis or kidney transplantation is a life-saving intervention, but is costly (USRDS, 2013c). Also, ESRD patients treated with renal replacement 
are at high risk for hospitalization or death, which is dependent in part on the quality of pre-ESRD care. Understanding the quality of pre-ESRD care for the elderly is a Centers for Medicaid and Medicare Services (CMS) priority (St. Peter, Khan, Ebben, Pereira, \& Collins, 2004).

Early detection and effective treatment are critical to slowing CKD progression to ESRD. Many studies have found early nephrology care to be associated with slowed progression of ESRD and improved quality outcomes (Echouffo-Techeugui \& Kengne; 2012; Fayer, Nascimento, \& Abdulkader, 2011). Once renal replacement therapy is imminent, receipt of three elements of care related to quality indicators established by the Centers for Medicare and Medicaid Services (CMS) results in reduced morbidity and mortality and improved quality outcomes for patients starting dialysis. These elements of pre-ESRD care include management of nephrology and dietary kidney care, as well as early placement of an arteriovenous fistula (AVF).

\section{Purpose Statement and Hypothesis}

This dissertation occurred in three parts: two studies and a related policy analysis. The purposes of the two studies were to examine age-related differences in the receipt of the following quality patient care indicators at the initiation of incident hemodialysis: (a) early nephrology management; (b) dietary consultation, and (c) the placement of an ateriovenous fistula (AVF). The first study was used as a pilot study in which the investigator learned to mine data contained in the U. S. Renal Data System (USRDS) and was focused on the relationship between age and placement of an AVF, prior to initiation of dialysis. The second study examined the relationships between age and other selected patient characteristics and receipt of all three quality care indicators. 
The author hypothesized that persons aged $\geq 67$ years receive a lower level of quality of care than younger persons based on receipt of the quality patient care indicators identified. To control for Medicare insurance eligibility at age 65 years the author chose age 67 (so a person could get signed up and have Medicare related access to care for at least a year) and then engaged in further stratification of ESRD patients into those less than 55 years of age, 55-66 years, 67-69 years, and over 80 years.

The purpose of the policy analysis was to gain a clearer understanding of the implications of differences in the interpretation and implementation of the Coordination Period policy in Puerto Rico for individual patients and health care delivery systems.

\section{Research Questions}

The first study addressed the first of the research questions posed below. The second study addressed questions one through three, and the policy analysis addressed question four.

1. Is there a difference in rate of placement of an AVF prior to initiation of hemodialysis between persons aged $\geq 67$ years and those $<67$ years?

2. Is there a difference in the rate of receipt of early nephrology care prior to initiation of hemodialysis between persons aged $\geq 67$ years and those $<67$ years?

3. Is there a difference in the rate of receipt of dietary care prior to initiation hemodialysis between persons aged $\geq 67$ years and those $<67$ years?

4. Is there a difference in the interpretation and implementation of the Coordination Period policy in Puerto Rico? 


\section{Methods}

The first two studies were retrospective correlational comparative descriptive studies. According to Polit and Beck (2012, p 224), " retrospective studies are best utilized when applied when a phenomenon existing in the present is linked to the phenomena that occurred in the past." Such designs specifically address phenomena in which the dependent variables' (quality care indicators) relationship to the independent variable (age) has already occurred. For this study, all data were retrospective. The United States Renal Disease System (USRDS) was used to extract pre-collected data over a five-year period, 2005 through 2010 . The studies examined aged-related differences in the receipt of the following three elements of pre-ESRD care: (a) receipt of care by a nephrologist at least 12 months prior to starting dialysis, (b) receipt of care by a dietician at any time prior to starting dialysis, and (c) whether a patient used an AFV at the first outpatient dialysis session.

The policy analysis was conducted over an 8-month period. We conducted a search of Centers for Medicaid \& Medicare Services (CMS) regulatory documents and interviewed stakeholders including healthcare professionals, patients, Puerto Rico healthcare agencies, and CMS personnel from the New York regional office. Greater details on the study methods are provided in the manuscripts included in Chapters 2, 3, and 4 respectively.

\section{Integration of the Three Papers}

The dissertation results were reported in three manuscripts. The first manuscript, Relationship between Age and Timely Placement of Vascular Access in Incident Patients on Hemodialysis, examined the use of an arteriovenous fistula (AVF) at the first 
outpatient hemodialysis treatment among U.S. incident patients on hemodialysis. The second manuscript, entitled Relationship between Age and Pre-End Stage Renal Disease Care in Hemodialysis Patients addressed age-related variations in the receipt of the composite of recommended care, including nephrologist and dietician care and use of AVF at first outpatient hemodialysis; and the third manuscript, Regional Variations in the Interpretation of the ESRD 30-Month Coordination Period, reviewed the 30-month ESRD Coordination Period policy in the Territory of Puerto Rico over an 8-month period. The policy analysis revealed regional variations in the interpretation of the coordination of ESRD benefits between the Territory of Puerto Rico and the U.S. regulatory guidelines. The three manuscripts together indicate that major efforts are needed to ensure comprehensive pre-ESRD care for patients of all ages with chronic kidney disease as well as a harmonizing of ESRD coordination of benefits for dialysis patients. The three manuscripts are included in Chapters 2,3, and 4, respectively.

\section{Summary}

The role of the nephrology nurse in the continuum of care for both the CKD and ESRD patient provides a number of expanded opportunities to assist in policy development and improved quality of care for this population. The research findings and policy analysis may help to fill gaps in the literature on age-related factors associated with quality care indicators for patients with ESRD and define future areas of research that would improve the care for all patients requiring advanced chronic disease care. In addition, the studies highlight the need for further exploration of specific interventions at provider and patient/family levels that may increase access to timely quality care for 
patients with advanced CKD and the development of a nurse practitioner specialty such as a nephrology nurse practitioner. The confluence of these findings can lead to national dialysis policy revision or development of new policies to better meet the needs of this patient population. 


\section{References}

Coresh, J., Selvin, E., Stevens, L. A., Manzi, J., Kusek, J. W., Eggers, P., . . Levey, A. S. (2007). Prevalence of chronic kidney disease in the United States. Jama, 298, 2038-2047.

Drawz, P. E., Babineau, D. C., \& Rahman, M. (2012). Metabolic complications in elderly adults with chronic kidney disease. Journal of American Geriatric Society, 60, 310-315. doi: $10.1111 / \mathrm{j} .1532-5415.2011 .03818 . \mathrm{x}$

Echouffo-Techeugui, J. B., \& Kengne, A. P. (2012). Risk models to predict chronic kidney disease and its progression: A systematic review. PLOS Medicine 9, e1001344. doi: 10.1371/journal.pmed.1001344

Erdem, E., Prada, S. I., \& Haffer, S. C. (2013). Medicare payments: How much do chronic conditions matter? Medicare \& Medicaid Research Review, 3, E1-E15.

Fayer, A. A., Nascimento, R., \&Abdulkader, R. (2011). Early nephrology care provided by the nephrologist alone is not sufficient to mitigate the social and psychological aspects of chronic kidney disease. Clinical Science, 66, 245-250.

doi:10.1590/S1807-59322011000200011

Polit, D. F., \& Beck, C. T. (2012). Nursing research: Generating and assessing evidence for nursing practice $\left(9^{\text {th }}\right.$ ed.). Philadelphia, PA: Lippincott Williams \& Wilkins.

St Peter, W. L., Khan, S. S., Ebben, J. P., Pereira, B. J., \& Collins, A. J. (2004). Chronic kidney disease: The distribution of health care dollars. Kidney International, 66, 313-321.

United States Renal Data System. (2013a). 2013 Atlas of CKD and ESRD. Retreived from http://www.usrds.org/atlas13.aspx 
United States Renal Data System (2013b). CKD in the general population. Retreived from: http://www.usrds.org/atlas13.aspx

United States Renal Data System (2013c). Costs of CKD. Retreived from: http://www.usrds.org/atlas13.aspx

Yan, G., Norris, K. C., Yu, A. J., Ma, J. Z., Greene, T., Yu, W., \& Cheung, A. K. (2013). The relationship of age, race, and ethnicity with survival in dialysis patients. Clinical Journal of the American Society of Nephrology, 8, 953-961. doi: 10.2215/CJN.09180912 
Running head: TIMELY PLACEMENT OF VASCULAR ACCESS

\section{Chapter 2}

\section{Manuscript 1}

Relationship between Age and Timely Placement of Vascular Access in Incident

Hemodialysis Patients 
Relationship between Age and Timely Placement of Vascular Access in Incident Hemodialysis Patients

Ruby Harford, RN, MSN, Mary Jo Clark, PhD, Keith C. Norris, MD, Guofen Yan, PhD

\section{Correspondence:}

Guofen Yan, $\mathrm{PhD}$

Department of Public Health Sciences

University of Virginia

Box 800717

Charlottesville, VA 22908-0717

Phone: 434-982-6422

Email: guofen.yan@virginia.edu

\section{Disclosure statement}

The authors declare that the manuscript has not been previously reported and is not under consideration for publication nor will be until a decision is made by the Nephrology Nursing Journal/Editor.

\section{Acknowledgements}

The authors would like to thank Wei Yu, MS at the University of Virginia for data managing and programming support. K.C.N is supported in part by NIH grant P20MD000182. G.Y is supported in part by NIH/NIDDK 5R01DK084200-04. The content 
is solely the responsibility of the authors and does not necessarily represent the official views of the National Institutes of Health.

\section{Author information and biographical statement}

Ruby Harford, RN, MSN, is a PhD candidate in the Hahn School of Nursing and Health Science at the University of San Diego, San Diego, CA, USA.

Mary Jo Clark, MSN, PhD, is a Professor in the Hahn School of Nursing and Health Science at the University of San Diego, San Diego, CA, USA.

Keith C. Norris, MD, is a senior faculty member, Division of General Internal Medicine and Health Services Research, David Geffen School of Medicine at UCLA, Los Angeles, CA, USA

Guofen Yan, $\mathrm{PhD}$, is a faculty biostatistician, School of Nursing and Department of Public Health Sciences, School of Medicine, University of Virginia, USA. 


\begin{abstract}
Background and purpose: Placement of an arteriovenous fistula (AVF) prior to initiating dialysis can affect clinical outcomes for patients who subsequently initiate chronic hemodialysis treatments. Age-related variation in receipt of a functioning AVF prior to initiating dialysis is not well known. The purpose of this study was to examine age-related rates in use of AVF at the first outpatient dialysis treatment among U.S. incident patients on hemodialysis.
\end{abstract}

Findings: Among 526,145 identified, the use of AVF at the first outpatient dialysis treatment was lower in the youngest ( $<55$ year) and oldest $(\geq 80$ year) vs. both 55-66 year and 67-79 year age groups. These findings persisted after adjusting for demographics, lifestyle behavior, employment and insurance status, physical/functional conditions, and comorbid conditions.

Conclusions: The presence of a functioning AVF at initial dialysis treatment varies by age. Modifying healthcare policy and/or expanding the role of the renal nurse practitioner should be considered to address this issue. 


\section{Introduction}

Chronic kidney disease (CKD) is a significant public health problem affecting over 20 million people in the United States (Centers for Disease Control and Prevention [CDC], 2012; Rettig, Norris, \& Nissenson, 2008). Based on the global contribution of CKD to premature mortality and morbidity, the World Health Organization (WHO) added CKD to its action plan for the prevention and control of noncommunicable diseases (WHO, 2010). Early detection and early nephrology care influence a multitude of public health consequences associated with psychosocial burdens and cost for patients with advanced CKD. Access to quality care for patients with advancing CKD may vary by race/ethnicity and geographic location (Yan, Cheung, et al., 2013). As such, arteriovenous fistula (AVF) placement prior to dialysis is an important indicator of preESRD care and a Centers of Medicare and Medicaid (CMS) clinical performance measure (CPM) (Arbor Research Collaborative for Health \& University of Michigan Kidney Epidemiology and Cost Center, 2013). Other performance measures monitored by CMS include the early management and surveillance of: (a) anemia, (b) mineral and bone disease, (c) infection control, and (d) kidney transplant list and waiting time, all of which contribute to the overall quality of care for patients with progressive CKD approaching the need for renal replacement therapy (RRT) (CMS, 2007).

The American Nephrology Nurses' Association (ANNA, 2013) has taken the position that all patients requiring maintenance hemodialysis therapy should have a functioning permanent vascular access in place before initiating hemodialysis and that access placement be established in stage 4 of CKD. AVF is strongly associated with lower rates of infection and mortality (Wish; 2010). One of every two patients starting 
hemodialysis is over 65 years of age (United States Renal Data System [USRDS] 2013) and many factors that influence AVF success such as comorbidities, smaller vessel size, and atherosclerotic disease are more prevalent in older patients and could influence the successful and timely placement of an AVF.

Two key factors contributing to the increasing prevalence of CKD are an aging population and the increasing prevalence of the leading CKD risk factors, diabetes and hypertension (Erdem, Prada, \& Haffer, 2013). People over 65 years of age comprise the fastest growing segment of the kidney failure population (Drawz, Babineau, \& Rahman, 2012; USRDS, 2013). Both diabetes and hypertension are more common with increasing age (Yan, Norris, et al., 2013). Diabetes now accounts for an estimated $45 \%$ of new cases of kidney failure and hypertension for an additional $30 \%$ (USRDS, 2013). The implications of aging and ESRD for the national healthcare system are substantial and understanding the quality of pre-ESRD care for the elderly is a CMS priority.

This study was conducted to assess potential age-related differences in AVF placement. We hypothesized that older patients were less likely to have a functioning AVF in place at the first dialysis treatment. To test this, we performed a national population analysis to assess age-related differences in the use of AVF at the first dialysis treatment.

\section{Methods}

\section{Data Sources and Study Population}

The study included all new maintenance dialysis patients treated with renal replacement therapy living in any of the 50 states or the District of Columbia who were 18 years of age or older at the time of initiation of dialysis and entered in the United 
States Renal Data System (USRDS) between 2005 and 2010. USRDS is a national population-based registry that includes almost all U.S. patients with kidney failure. In 2005, the CMS ESRD Medical Evidence (ME) Report was revised to include information on pre-renal failure care received during the year prior to initiation of renal replacement therapy, so data collection included all patients who completed the revised ME form.

\section{Study Variables}

Data extracted from the USRDS included whether a patient used an AVF at the first outpatient hemodialysis session. Additional data was extracted to assess whether or not patients had received care by a nephrologist at least 12 months prior to starting dialysis, and whether or not patients had received care by a dietitian at any time prior to starting dialysis. Data on patient variables such as demographic characteristics, employment status, health insurance coverage, and comorbid conditions were also obtained from the USRDS. Data included gender, race and ethnicity, age at dialysis onset, lifestyle behavior (current smoking), health care access, health insurance status at the initiation of dialysis, physical/functional conditions, and various comorbid conditions (e.g., diabetes, hypertension, cardiovascular diseases, and cancer). Employment status at six months prior to ESRD was used as a proxy measure of access to health care. Each patient's health insurance status was assigned to one of four categories: no insurance, Medicaid only, Medicare only, and other including employer-group only and/or two or more carriers. The study was approved by the Institutional Review Board (IRB) for Health Sciences Research at University of Virginia. 


\section{Statistical Analysis}

We assessed the differences in use of an AVF at the first outpatient dialysis session by comparing percentages of patients on hemodialysis with AVF across four age categories ( $<55$ years, 55-66 years, $67-79$ years, $\geq 80$ years of age). We examined the unadjusted odds ratios with logistic regression and then the odds ratios adjusted for patient characteristics, including demographics, lifestyle behavior, employment status and insurance, physical/functional conditions, and various comorbid conditions as listed in Table 1. The purpose of adjusted analysis was to assess whether the age related differences in use of an AVF at the first outpatient dialysis session persisted after accounting for the patient factors considered. To compare these four age groups, we present results of six pairwise comparisons by the order of age group: age groups of 5566 years, $67-79$ years, and $\geq 80$ years compared with the youngest age group ( $<55$ years). Then age groups of 67-79 years and $\geq 80$ years compared with the second youngest age group (55-66 years), and finally the age group of $\geq 80$ years compared with the third youngest group (67-79 years).

\section{Results}

\section{Patient Characteristics}

Patient characteristics are presented in Table 1. Of the 559,056 patients reviewed, $153,611(27.5 \%)$ were $<55$ years of age, $154,126(27.6 \%)$ were $55-66$ years of age, $168,044(30.0 \%)$ were $67-79$ years of age, and $83,275(14.9 \%)$ were $\geq 80$ years of age. Compared to older patients, those $<55$ years of age were more likely to be male, of a racial/ethnic minority, uninsured, less likely to be employed at 6 months before ESRD, and less likely to have most comorbid medical conditions. 


\section{Regression Analyses}

Our logistic regression for AVF was restricted to the subset of incident patients on hemodialysis at the ESRD onset $(N=526,145)$. Unadjusted logistic regression analyses were first performed comparing the likelihood of using an AVF at first dialysis (Table 2) among the four age groups. Six pair-wise comparisons were made: 55-66 years, 67-79 years, and $\geq 80$ years against the reference group ( $<55$ years); $67-79$ years, and $\geq 80$ years compared to the 55-66 year-old group; and $\geq 80$ years compared to the 67-79 year-old group. The likelihood of using an AVF at first dialysis was lower in the youngest and oldest groups ( $<55$ years and $\geq 80$ years) compared to the 55-66 and 67-79 year-old groups. The likelihood of using an AVF at first dialysis was similar in 55-66 and 67-79 year-old groups. Likelihood was also comparable between the $<55$ years and $\geq 80$ years age groups. After adjusting for multiple patient characteristics, including demographics, lifestyle behavior, employment and insurance status, physical/ functional conditions, and comorbid conditions listed in Table 1, the likelihood of using an AVF at first dialysis remained lower for the youngest and oldest groups ( $<55$ years and $\geq 80$ years) in comparison to the 55-66 and 67-79 year-old groups (Table 3). Sensitivity analyses revealed similar patterns between age and receipt of pre-ESRD nephrology care $\mathbb{N}=$ $491,992)$ as well as age and receipt of pre-ESRD dietician care $(\mathrm{N}=450,626)$ (data not presented).

\section{Discussion}

This is the first study to our knowledge that examined age-related differences in the use of an arteriovenous fistula at the initial hemodialysis treatment. Two specific groups were identified as having the lowest rate of AVF use at their first hemodialysis 
treatment, those $<55$ years of age and those $\geq 80$ years of age. Our findings are consistent with those of Lilly et al. who reported lower odds of AVF placement among 195,756 adult incident hemodialysis patients older than 85 years of age (but not younger patients) as well as for women, blacks, Hispanics, and persons with diabetes, peripheral vascular disease, congestive heart failure, other cardiac disease, and underweight (Lilly et al., 2012). In contrast to our analysis, they examined patients with 6 months or more of prior nephrology care which may have pre-selected younger patients with insurance and may explain why they only found the lower AVF rates among older patients.

A similar analysis by Patibandla et al. found increasing age, female sex, black race, lower body mass index, urban location, certain comorbidities, and shorter pre-endstage renal disease nephrology care were associated with a significantly lower likelihood of AVF being placed, even if it was not ready for use at the first dialysis treatment, among 118,767 incident hemodialysis patients $\geq 67$ years of age (Patibandla et al., 2013). This study differed slightly from ours in that Patibandla et al. specifically looked at AVF being placed prior to dialysis, in contrast to AVF being used at first dialysis as examined in our analysis.

Study limitations include the cross sectional nature of the data that only allows us to assess relationships and not causal effects. In addition, a prior report of disagreement between information from the CMS Medical Evidence Report and Medicare physician claims for pre-ESRD care suggests the validity of CMS Medical Evidence Report is not clear (Kim, Desai, Chertow, \& Winkelmayer, 2012). We examined pre-ESRD nephology and dietician care and found results similar to use of an AVF at initial dialysis, recognizing that timing of pre-ESRD care is inherently less definitive than use of an AVF 
at dialysis. Finally, not all patients may be good candidates for an AVF (Gomes, Schmidt, \& Wish, 2013), but that should not prevent the renal community from striving to meet Healthy People 2020 goals for pre-ESRD care (USRDS, 2013).

The recommendations from our study include the need for promoting more universal insurance coverage such as expanded Medicaid and similar coverage for uninsured as should be provided with the new Affordable Care Act (Health Resources and Services Administration, 2011). In addition, prospective studies are needed to examine specific interventions at provider and patient/family levels that may increase access to timely quality care for patients with advanced CKD.

\section{Implications for Nephrology Nurses}

These findings should be a reminder to nephrology nurses, as members of the preESRD and ESRD patient care team and, in some cases, primary care providers, to not only maintain diligence in facilitating quality pre-ESRD care but to be cognizant of the additional risks that exist for younger ( $<55$ years) and older $(\geq 80$ years) patients related to obtaining an AVF for use at the first dialysis treatment. Working closely with social workers and family to address key socio-demographic issues may be important for engaging and motivating many patients. Strategies to enhance care coordination between primary care providers and the CKD/ESRD team should be explored by the all members of the health care team, including nurses and nurse practitioners. There is growing recognition and acceptance across multidisciplinary programs that nurse practitioners can make a positive contribution to healthy outcomes through an expanded role in working with public health agencies, community-based organizations (CBOs), and in-patient units. Polkinghorne et al. reported an increase in AVF placement from less than $50 \%$ to 
$65 \%$ following the introduction of a multifaceted intervention that included a vascular access nurse coordinator and an algorithm to prioritize surgery (Polkinghorne, Seneviratne, \& Kerr, 2009). The present findings of both low rates of AVF use at the first dialysis treatment and disparities of AVF use across age groups should prompt a call to action by ANNA for nurses to more aggressively pursue a substantive leadership role on the CKD/ESRD team. Initiatives may include the use of nurse practitioners and/or clinical nurse specialists in CKD clinics as suggested by Davis and Zuber (2013). A joint initiative between ANNA and the American Society of Nephrology and/or Renal Physicians Association may help to address the issue of ensuring the highest quality of care for patients with advanced CKD. 


\section{References}

American Nephrology Nurses' Association. (2013). Vascular access for hemodialysis.

Retrieved from:

http://www.annanurse.org/download/reference/health/position/vascAccess.pdf

Arbor Research Collaborative for Health \& University of Michigan Kidney

Epidemiology and Cost Center. (2013). End stage renal disease quality measures.

Retrieved from: http://www.dialysisreports.org/ESRDMeasures.aspx

Centers for Disease Control and Prevention. (2012). Chronic kidney disease initiative:

Protecting kidney health. Retrieved from:

http://www.cdc.gov/diabetes/projects/pdfs/ckd_factsheet.pdf

Centers for Medicare and Medicaid. (2007). 2007 annual report, end stage renal disease

Clinical Performance Measures Project. Retrieved from:

http://www.cms.gov/Medicare/End-Stage-Renal-

Disease/CPMProject/Downloads/ESRDCPMYear2007Report.pdf

Davis, J. S., \& Zuber, K. (2013). Implementing patient education in the CKD clinic.

Advances in Chronic Kidney Disease, 20, 320-325. doi:

10.1053/j.ackd.2013.04.004

Drawz, P. E., Babineau, D. C., \& Rahman, M. (2012). Metabolic complications in elderly adults with chronic kidney disease. Journal of American Geriatric Society, 60, 310-315. doi: $10.1111 / \mathrm{j} .1532-5415.2011 .03818 . x$

Erdem, E., Prada, S. I., \& Haffer, S. C. (2013). Medicare payments: How much do chronic conditions matter? Medicare \& Medicaid Research Review, 3(2), E1-E15. 
Gomes, A., Schmidt, R., \& Wish, J. (2013). Re-envisioning Fistula First in a patientcentered culture. Clinical Journal of the American Society of Nephrology, 8, 1791-1797. doi: $10.2215 / \mathrm{cjn} .03140313$

Health Resources and Services Administration. (2011). Affordable Care Act helps expand future primary care workforce. Retrieved from: http://www.hrsa.gov/about/news/pressreleases/nhscscholarship.html

Kim, J. P., Desai, M., Chertow, G. M., \& Winkelmayer, W. C. (2012). Validation of reported predialysis nephrology care of older patients initiating dialysis. Journal of the American Society of Nephrology, 23, 1078-1085. doi:

\subsection{1/asn.2011080871}

Lilly, M. P., Lynch, J. R., Wish, J. B., Huff, E. D., Chen, S. C., Armistead, N. C., \& McClellan, W. M. (2012). Prevalence of arteriovenous fistulas in incident hemodialysis patients: correlation with patient factors that may be associated with maturation failure. American Journal of Kidney Disease, 59, 541-549. doi: 10.1053/j.ajkd.2011.11.038

Patibandla, B. K., Narra, A., Desilva, R., Chawla, V., Vin, Y., Brown, R. S., \& GoldfarbRumyantzev, A. S. (2013). Disparities in arteriovenous fistula placement in older hemodialysis patients. Hemodialysis International, [Epub ahead of print], doi: 10.1111/hdi.12099

Polkinghorne, K. R., Seneviratne, M., \& Kerr, P. G. (2009). Effect of a vascular access nurse coordinator to reduce central venous catheter use in incident hemodialysis patients: A quality improvement report. American Journal of Kidney Disease, 53, 99-106. doi: 10.1053/j.ajkd.2008.06.026 
Rettig, R. A., Norris, K., \& Nissenson, A. R. (2008). Chronic kidney disease in the United States: A public policy imperative. Clinical Journal of the American Society of Nephrology, 3, 1902-1910. doi: 10.2215/CJN.02330508

United States Renal Data System. (2013). USRDS 2013 annual data report: Atlas of chronic kidney disease and end stage-renal disease in the United States. Bethesda, MD: National Institutes of Health.

Wish, J. B. (2010). Vascular access for dialysis in United States: Progress, hurdles, controversies and the future. Seminars in Dialysis, 23, 614-618. doi: 10.1111/J.1525-139x.2010.00797.x

World Health Organization (2010). Global status report on noncommunicable diseases. Retrieved from http://www.who.int/chp/ncd global status report/en/index.html Yan, G., Cheung, A. K., Ma, J. Z., Yu, A. J., Greene, T., Oliver, M. N., . . Norris, K. C. (2013). The associations between race and geographic area and quality-of-care indicators in patients approaching ESRD. Clinical Journal of the American Society of Nephrology, 8, 610-618. doi: 10.2215/CJN.07780812

Yan, G., Norris, K. C., Yu, A. J., Ma, J. Z., Greene, T., Yu, W., Cheung, A. K. (2013). The relationship of age, race, and ethnicity with survival in dialysis patients. Clinical Journal of the American Society of Nephrology, 8, 953-61. doi: 10.2215/CJN.09180912. 
Table 1. Patient Characteristics by Age Group

\begin{tabular}{|c|c|c|c|c|}
\hline \multirow[b]{2}{*}{ Patient characteristic } & \multicolumn{4}{|c|}{ Age group } \\
\hline & $\begin{array}{c}<55 \text { years } \\
(n=153,611)\end{array}$ & $\begin{array}{l}55-66 \text { years } \\
(n=154,126)\end{array}$ & $\begin{array}{l}67-79 \text { years } \\
(n=168,044)\end{array}$ & $\begin{array}{l}\geq 80 \text { years } \\
(n=83,275)\end{array}$ \\
\hline Age (years), Mean \pm SD & $43.4 \pm 8.9$ & $60.7 \pm 3.4$ & $72.9 \pm 3.7$ & $84.1 \pm 3.4$ \\
\hline Male sex $(\%)$ & 59.2 & 56.0 & 54.5 & 54.2 \\
\hline \multicolumn{5}{|l|}{ Race/ethnicity (\%) } \\
\hline Non-Hispanic white & 37.3 & 50.0 & 61.9 & 72.8 \\
\hline Non-Hispanic black & 40.0 & 30.5 & 22.6 & 15.7 \\
\hline Hispanic & 16.9 & 14.1 & 10.6 & 7.1 \\
\hline Other & 5.8 & 5.4 & 4.9 & 4.3 \\
\hline $\begin{array}{l}\text { Employed at } 6 \text { months before end- } \\
\text { stage renal disease (\%) }\end{array}$ & 66.3 & 79.4 & 91.3 & 93.7 \\
\hline \multicolumn{5}{|l|}{ Insurance coverage (\%) } \\
\hline No insurance & 18.3 & 8.4 & 1.0 & 0.6 \\
\hline Medicaid only & 23.7 & 14.5 & 2.4 & 1.4 \\
\hline Medicare only & 5.9 & 12.9 & 22.1 & 21.4 \\
\hline Other/combination & 52.0 & 64.2 & 74.5 & 76.7 \\
\hline Current smoker (\%) & 9.8 & 7.8 & 4.4 & 1.6 \\
\hline \multicolumn{5}{|l|}{ Physical/ functional conditions } \\
\hline Inability to ambulate (\%) & 3.4 & 6.6 & 8.7 & 11.1 \\
\hline Inability to transfer (\%) & 1.5 & 3.0 & 4.5 & 6.0 \\
\hline $\begin{array}{l}\text { Needs assistance with daily } \\
\text { activities (\%) }\end{array}$ & 6.1 & 10.2 & 14.1 & 19.0 \\
\hline $\begin{array}{l}\text { Institutionalized - Nursing } \\
\text { Home (\%) }\end{array}$ & 2.6 & 5.6 & 9.1 & 13.7 \\
\hline \multicolumn{5}{|l|}{ Comorbid conditions } \\
\hline Hypertension (\%) & 83.7 & 85.2 & 85.0 & 84.5 \\
\hline Diabetes (\%) & 46.9 & 63.7 & 56.8 & 39.9 \\
\hline Congestive heart failure (\%) & 19.2 & 32.4 & 39.7 & 45.7 \\
\hline $\begin{array}{l}\text { Arteriosclerotic heart disease } \\
(\%)\end{array}$ & 8.5 & 20.6 & 28.6 & 31.9 \\
\hline
\end{tabular}




\begin{tabular}{|c|c|c|c|c|}
\hline Other heart diseases (\%) & 8.4 & 15.5 & 21.3 & 25.3 \\
\hline $\begin{array}{l}\text { Cerebrovascular accident/ } \\
\text { transient ischemic attack (\%) }\end{array}$ & 5.3 & 10.1 & 12.1 & 12.0 \\
\hline Peripheral vascular disease (\%) & 7.4 & 14.4 & 17.9 & 17.2 \\
\hline Amputation (\%) & 3.3 & 4.2 & 2.8 & 1.4 \\
\hline $\begin{array}{l}\text { Chronic obstruction pulmonary } \\
\text { disease }(\%)\end{array}$ & 3.7 & 9.2 & 12.9 & 12.4 \\
\hline Cancer $(\%)$ & 2.7 & 6.6 & 10.6 & 12.1 \\
\hline \multicolumn{5}{|l|}{ Outcome $^{\mathrm{a}}$} \\
\hline AVF at first dialysis (\%) & 12.4 & 14.6 & 14.7 & 12.3 \\
\hline $\begin{array}{l}\text { Receipt of nephrologist care at } \\
\text { least } 12 \text { months before ESRD } \\
(\%)\end{array}$ & 22.7 & 27.1 & 29.6 & 28.0 \\
\hline $\begin{array}{l}\text { Receipt of dietitian care at any } \\
\text { time before ESRD }(\%)\end{array}$ & 10.3 & 11.8 & 11.6 & 10.6 \\
\hline
\end{tabular}

- Sample size varied: $\mathrm{N}=526,145$ for $\mathrm{AVF}, \mathrm{N}=491,992$ for nephrologist care, and $\mathrm{N}=450,626$ for dietitian care. 
Table 2. Unadjusted Odds Ratios of Having an Arteriovenous Fistula at First Hemodialysis

\begin{tabular}{|l|l|l|l|}
\hline Age Group & Odds ratio & $95 \%$ CI & P value \\
\hline $55-66$ vs. $<55$ years & 1.21 & $(1.18-1.23)$ & 0.000 \\
\hline $67-79$ vs. $<55$ years & 1.22 & $(1.19-1.24)$ & 0.000 \\
\hline$\geq 80$ vs. $<55$ years & 0.99 & $(0.96-1.01)$ & 0.313 \\
\hline \multicolumn{5}{|c|}{} \\
\hline $67-79$ vs. $55-66$ years & 1.01 & $(0.99-1.03)$ & 0.354 \\
\hline$\geq 80$ vs. $55-66$ years & 0.82 & $(0.80-0.84)$ & 0.000 \\
\hline \multicolumn{5}{|l}{} \\
\hline$\geq 80$ vs. $67-79$ years & 0.81 & $(0.79-0.83)$ & 0.000 \\
\hline
\end{tabular}


Table 3. Adjusted Odds Ratios of Having an Arteriovenous Fistula at First Hemodialysis

\begin{tabular}{|l|l|l|l|}
\hline Age Group & Odds ratio" & $95 \%$ CI & P value \\
\hline $55-66$ vs. $<55$ years & 1.18 & $(1.15-1.21)$ & 0.000 \\
\hline $67-79$ vs. $<55$ years & 1.16 & $(1.14-1.19)$ & 0.000 \\
\hline$\geq 80$ vs. $<55$ years & 0.98 & $(0.95-1.01)$ & 0.173 \\
\hline \multicolumn{4}{|l|}{} \\
\hline $67-79$ vs. $55-66$ years & 0.99 & $(0.97-1.01)$ & 0.208 \\
\hline$\geq 80$ vs. $55-66$ years & 0.83 & $(0.81-0.85)$ & 0.000 \\
\hline \multicolumn{4}{|l|}{} \\
\hline$\geq 80$ vs. $67-79$ years & 0.84 & $(0.82-0.86)$ & 0.000 \\
\hline
\end{tabular}

adjusted for the patient characteristics listed in Table 1. 


\section{Copyright Permission}

On Dec 1, 2014, at 5:43 AM, Joe Tonzelli <joe.tonzelli@aji.com> wrote:

Hi Ruby,

Permission is granted to include your article in your dissertation bounding. If you require more information or clarification, please feel free to reach out to me in the afternoon today at my number below.

Thanks.

Joe

Joe Tonzelli

Editorial Coordinator, Nephrology Nursing Journal

Anthony J. Jannetti, Inc.

East Holly Ave, Box 56

Pitman, NJ 08071

PH: 856.256.2344

FAX: 856.589.7463

Find ANNA on Twitter and Facebook!

"Be excellent to each other." - Abraham Lincoln 


\section{Chapter 3}

\section{Manuscript 2}

Relationship between Age and pre-End Stage Renal Disease Care in Hemodialysis

Patients 
Relationship between Age and Pre-End Stage Renal Disease Care in Elderly Hemodialysis Patients

Rubette Harford, MSN, PhD(c), Mary Jo Clark, PhD, RN, Keith C. Norris, MD, PhD, Jane Georges, PhD, RN, Guofen Yan, $\mathrm{PhD}$

\section{Correspondence:}

Guofen Yan, PhD

Department of Public Health Sciences

University of Virginia

Box 800717

Charlottesville, VA 22908-0717

Phone: 434-982-6422

Email: guofen.yan@virginia.edu

\section{Disclosure statement}

The authors declare that the manuscript has not been previously reported and is not under consideration for publication nor will be until a decision is made by the Nephrology Nursing Journal/Editor.

\section{Acknowledgements}

The authors would like to thank Wei Yu, MS at the University of Virginia for data managing and programming support. K.C.N is supported in part by NIH grant P20- 
MD000182, UL1TR000124, P30AG021684. G.Y is supported in part by NIH/NIDDK 5R01DK084200-04. The content is solely the responsibility of the authors and does not necessarily represent the official views of the National Institutes of Health.

\section{Author information and biographical statement}

Rubette Harford, RN, MSN, $\mathrm{PhD}(\mathrm{c})$, is a PhD candidate, Hahn School of Nursing and Health Science, University of San Diego, San Diego, CA, USA. She is a member of ANNA's California Riverside Chapter.

Mary Jo Clark, PhD, RN, is a Professor, Hahn School of Nursing and Health Science, University of San Diego, San Diego, CA, USA.

Keith C. Norris, MD, $\mathrm{PhD}$, is a senior faculty member, Division of General Internal Medicine and Health Services Research, David Geffen School of Medicine at UCLA, Los Angeles, CA, USA

Jane Georges is an Associate Professor, Hahn School of Nursing and Health Science, University of San Diego, San Diego, CA, USA.

Guofen Yan, $\mathrm{PhD}$, is a faculty biostatistician, School of Nursing and Department of Public Health Sciences, School of Medicine, University of Virginia, USA. guofen.yan@virginia.edu 


\begin{abstract}
Background and objectives: Receipt of pre-end-stage renal disease (ESRD) clinical care can improve outcomes for maintenance hemodialysis (MHD) patients. The study addressed age-related variations in receipt of a composite of recommended care to include nephrologist and dietician care and use of arterio-venous fistula at first outpatient hemodialysis.
\end{abstract}

Findings: Less than 2\% of MHD patients received all three forms of pre-ESRD care, and $63.3 \%$ received none of the three elements of care. The mean number of pre-ESRD care elements received by the oldest group ( $\geq 80$ years) did not differ from the youngest group ( $<55$ years), but was less than the 55-66 and 67-79 years groups; adjusted ratios of 0.93 $(0.92-0.94 ; \mathrm{p}<0.001)$ and $0.94(0.92-0.95 ; \mathrm{p}<0.001)$, respectively.

Conclusions: A major effort is needed to ensure comprehensive pre-ESRD care for all patients with advanced CKD, especially for the youngest and oldest patient groups, who were less likely to receive recommended pre-ESRD care. 


\section{Introduction}

Chronic kidney disease (CKD) is a major public health problem affecting one in eight adults (Levey, Andreoli, DuBose, Provenzano, \& Collins, 2007) and leading to endstage renal disease (ESRD) requiring treatment with renal transplantation or dialysis (Stevens \& Levin, 2013) or premature mortality (Go, Chertow, Fan, McCulloch, \& Hsu, 2004). The psychosocial and economic burden of ESRD has challenged the nephrology community to promote early detection and intervention to improve outcomes for patients with CKD ( Rettig, Vargas, Norris, \& Nissenson, 2010; Rettig, Norris, \& Nissenson, 2008).

For patients with advanced $\mathrm{CKD}$, early referral for specialty care may slow the decline in renal function (Chen et al., 2008; Jones, Roderick, Harris, \& Rogerson, 2006) and reduce subsequent mortality (Jones, Roderick, Harris, \& Rogerson, 2006). It is also associated with reduced progression to ESRD and improved quality of life and clinical outcomes after the initiation of dialysis (Brick \& Ellis, 2009; Lee et al., 2014; Smart, Dieberg, Ladhani, \& Titus, 2014). In addition to improving patient outcomes, timely preESRD care can reduce health care costs for those needing replacement renal therapy (Ismail, Neyra, \& Hakim, 1998; Stroupe et al., 2011). Because of these reports, clinical practice guidelines now recommend that all patients in advanced stages (stage 4 and 5) of CKD receive nephrology care (Levey, Atkins, et al., 2007; Stevens \& Levin, 2013). Unfortunately, as many as $30-50 \%$ of patients undergoing maintenance dialysis in the United States do not receive adequate pre-ESRD care before starting dialysis (United States Renal Data System [USRDS] 2013).

The issue of quality care for patients with advanced CKD is an important concern 
for the nephrology nursing community (American Nephrology Nurses' Association [ANNA], 2013; Harford, Clark, Norris \& Yan, in press) and the American Nephrology Nurses' Association has taken the position that all patients requiring maintenance hemodialysis therapy should have quality pre-ESRD care prior to initiating hemodialysis (ANNA, 2013). The nursing paradigm of four interrelated concepts of person, health, environment, and nursing described by McEwen and Wills (2007) provides an ideal conceptual framework for pre- ESRD education. This is particularly important since nurses are frequently key members of the pre-ESRD education team, and holistic, patientcentered care and education may assist the individual with advanced CKD to receive the necessary pre-ESRD care and achieve optimal health (Key, 2008).

Two key factors contributing to the increasing prevalence of CKD are an aging population and the increasing prevalence of diabetes and hypertension, the leading CKD risk factors (Erdem, Prada, \& Haffer, 2013). While ESRD affects persons of all ages, it is more common with advancing age, with one of every two patients starting hemodialysis over 65 years of age. People in this age group comprise the fastest growing segment of the kidney failure population (Drawz, Babineau, \& Rahman, 2012; USRDS, 2013), and those over 80 years of age are at even higher risk for ESRD (USRDS 2013).

Diabetes now accounts for an estimated $45 \%$ of new cases of kidney failure and hypertension for an additional 30\% (USRDS, 2013). These conditions are even more common among ESRD patients with increasing age (Yan et al., 2013). Age has been associated with differences in the presence of a functioning arteriovenous fistula (AVF) at initial dialysis treatment, suggesting age may affect receipt of pre-ESRD care (Harford, Clark, Norris, \& Yan, in press). For example, an analysis of the Department of Veterans 
Affairs (VA) and Medicare healthcare systems found that one-third of older veterans initiating dialysis did not receive pre-ESRD nephrology care (Fischer et al., 2010). The implications of aging and ESRD for the national healthcare system are substantial and understanding the quality of pre-ESRD and ESRD care for the elderly are Centers for Medicare and Medicaid Services (CMS) priorities.

To better determine if age influences the quality of pre-ESRD care, we conducted a national population analysis to assess potential age-related differences in the composite of three pre-ESRD care elements that are part of the CMS clinical performance metrics: (a) receipt of nephrology care at least 12 months prior to the initiation of dialysis, (b) dietitian care prior to the initiation of dialysis, and (c) the use of AVF for the first dialysis treatment in maintenance hemodialysis patients (MHD). We hypothesized that older patients were less likely to have received the composite of CMS recommended pre-ESRD care elements than their younger counterparts.

\section{Methods}

\section{Data Sources and Study Population}

The study included all new MHD patients treated with renal replacement therapy living in any of the 50 states or the District of Columbia who were 18 years of age or older at the time of initiation of dialysis and entered in the United States Renal Data System (USRDS) between 2005 and 2010. USRDS is a national population-based registry that includes almost all U.S. patients with kidney failure. In 2005, the CMS ESRD Medical Evidence (ME) Report was revised to include information on pre-ESRD care that patients had received during the year prior to initiation of renal replacement therapy. Data collection included all patients who completed the revised ME form. 


\section{Study Variables}

Data extracted from the USRDS included the three elements of recommended pre-ESRD care: (a) receipt of care by a nephrologist at least 12 months prior to starting dialysis, (b) receipt of care by a dietitian at any time prior to starting dialysis, and (c) whether a patient used an AVF at the first outpatient dialysis session. Data extracted also included gender, race and ethnicity, age at dialysis onset, lifestyle behavior (current smoking), health care access, health insurance status at the initiation of dialysis, physical/functional conditions, and various comorbid conditions (e.g., diabetes, hypertension, cardiovascular diseases, and cancer). Employment status at six months prior to ESRD was used as a proxy measure of access to health care. Each patient's health insurance status was assigned to one of four categories: no insurance, Medicaid only, Medicare only, and other, including employer-group only and/or two or more carriers. The study was approved by the Institutional Review Board (IRB) at University of Virginia and the IRB at the University of San Diego.

\section{Statistical analysis}

The outcome was the composite of the three pre-ESRD care elements for MHD patients, measured as the total number of care elements received per patient (range: $0-3$ ). We used Poisson regression, which is appropriate for frequency data, to compare four age categories ( $<55$ years, 55-66 years, 67-79 years, $\geq 80$ years of age), expressed as ratios of the mean number of care elements received by respective age groups compared to that in the reference group. The ratios were adjusted for patient characteristics, including demographics, lifestyle behavior, employment status and insurance, physical/functional conditions, and various comorbid conditions listed in Table 1. The purpose of adjusted 
analysis was to assess whether any age-related differences in the composite of three preESRD care elements received persisted after accounting for the patient factors considered. To compare these four age groups, we present results of pairwise comparisons by the order of age group: age groups of 55-66 years, $67-79$ years, and $\geq 80$ years compared with the youngest age group ( $<55$ years). Then age groups of 67-79 years and $\geq 80$ years were compared with the second youngest age group (55-66 years), and finally the age group of $\geq 80$ years compared with the third youngest group (67-79 years).

\section{Results}

As indicated in Table $1,15.1 \%$ of the 412,291 patients were over 80 years of age, with the rest relatively evenly distributed among the three other age groups. Compared to older patients, those $<55$ years of age were more likely to be male, of a racial/ethnic minority group, and uninsured, less likely to be employed at 6 months before ESRD, and less likely to have most comorbid medical conditions. In contrast, those $\geq 80$ years were more likely to be non-Hispanic white, have insurance, have been employed, and have functional disabilities than other age groups.

Table 2 presents findings related to receipt of pre-ESRD care elements for the total sample as well as for specific age groups. Nearly two-thirds of patients (63.3\%) did not receive any of the three care elements considered, $25 \%$ received one care element, and roughly $10 \%$ received two care elements. Less than $2 \%$ received all three elements of recommended pre-ESRD care. Overall, the average number of care elements received by patients in the entire cohort was 0.50 . Among patients less than 55 years of age, the mean was 0.43 , increasing to 0.52 for those in 55-66 year age group and 0.55 for those 67-79 years of age and then declining to 0.51 for the oldest group. 


\section{Regression Analyses}

Both unadjusted and adjusted Poisson regression analyses were performed comparing the mean number of pre-ESRD care elements received (nephrologist care, dietitian care, AVF used at initial dialysis) between the age groups (Table 3). In unadjusted analyses, the older cohorts, including those over 80 years of age were significantly more likely to have received the recommended composite care than the youngest age group ( $<55$ years). However, those over 80 years received less care than either the 55- to 66-year-olds (ratio $-0.97[0.96-0.99])$ or the 67 - to $79-$ year-olds (ratio -0.92 [0.91-0.93]).

After adjusting for multiple demographic, clinical, and pre-ESRD health-care access factors, there were no longer significant differences in the number of recommended care elements received by the oldest $(\geq 80$ years) and youngest ( $<55$ years) groups. However the oldest ( $\geq 80$ years) group still received significantly less care than the 55- to 66-year-old group (ratio - 0.93 [0.92-0.94]) and the 67- to 79-year-old group (ratio - $0.94[0.92-0.95])$ (See Table 3).

\section{Discussion}

This is the first study to our knowledge that examined at the national level agerelated differences in the receipt of the composite of pre-ESRD nephrology and dietitian care as well as the use of AVF at the first dialysis treatment. After multiple statistical adjustments for patient level factors, receipt of the recommended elements of pre-ESRD care was lower in the youngest and oldest groups ( $<55$ years and $\geq 80$ years) in comparison to 55-66 and 67-79 year old groups. In addition we noted that pre-ESRD care was extremely low with less than $2 \%$ of the MHD population reported to have received all three forms of recommended care. 
Our findings of lower receipt of composite pre-ESRD care are consistent with those of Lilly et al. (2012), who reported lower odds of AVF placement among 195,756 adult incident MHD patients over 85 years of age. The current study builds upon our prior report of lower odds of AVF placement among MHD patients $\geq 80$ years of age by expanding to assess the composite of pre-ESRD care elements (Harford et al., in press). Our findings were surprising as we hypothesized that the older patients would receive lower levels of composite pre-ESRD care. We expected younger patients to have lower unadjusted rates of pre-ESRD care due to less insurance coverage (USRDS, 2013), but after adjusting for this and other patient-level factors, we anticipated they would no longer have lower levels of pre-ESRD care. Our primary hypothesis was that the oldest patients would receive lower levels of composite pre-ESRD care based on prior evidence of lesser delivery of health care for the aging population after adjusting for insurance coverage. Interestingly, we found it was both the oldest and youngest groups that received lower levels of composite pre-ESRD care after adjusting for patient factors.

It is known that nephrologist care prior to ESRD results in improved clinical outcomes. Under a nephrologist's care, patients are more likely to receive care from a renal care team and receive other important pre-ESRD care services, including dietitian referral, timely placement of AVF, and enhanced management of multiple co-morbid conditions (Fayer, Nascimento, \& Abdulkader, 2011; Prakash et al., 2010). In this study, we examined how the rates of receiving these important care indicators varied among different age groups of ESRD patients.

The elderly constitute a substantial and growing portion of the ESRD population, and rates of treated ESRD among the older elderly ( $\geq 80$ years) have risen by more than 
$50 \%$ in the last decade (Tamura, 2009) Quality of life results are mixed with older ESRD patients reporting similar levels of mental well being but reduced physical well-being in comparison to their younger ESRD peers (Tamura, 2009). One of the first dilemmas encountered in the management of elderly patients approaching ESRD is deciding whether to initiate renal replacement therapy (Vachharajani et al., 2014). Once a decision has been made to initiate renal replacement therapy these patients should receive the same quality of care as their younger ESRD peers. This can be challenging at times given the high prevalence of comorbidities and complex quality of life issues associated with the older ESRD population. These factors pose substantial challenges for clinicians, such as technical difficulties in the placement of an arteriovenous fistula, that complicate clinical decision-making and provision of optimal care, (Vachharajani et al., 2014). By examining the composite of pre-ESD care elements, we are better able to examine the broader risk for suboptimal care for the elderly. This approach provides an expansive view not limited to technical vascular issues associated with aging.

Our findings of an extremely low rate of composite pre-ESRD care likely reflects a combination of factors from fragmented care for patients with advanced CKD (Rastogi, Linden, \& Nissenson, 2008), to limited or no insurance for many with advanced CKD (Owen \& Norris, 1994), and not having a nephrologist and the nephrology team as the primary care provider for patients with advanced $\mathrm{CKD}$ as they prepare to transition to ESRD (Owen \& Norris, 1994; Rastogi, Linden, \& Nissenson, 2008). Regardless of the reason(s), our findings highlight a major gap in pre-ESRD care delivery and underscore the need for new models of care to bridge this gap, such as nurse directed care and/or health navigators. 
Study limitations include the cross sectional nature of the study design that only allows us to assess associations and not causal effects. Not all patients may be good candidates for an AVF, especially older elderly (Gomes, Schmidt, \& Wish, 2013), but that is why we also examined other aspects of pre-ESRD care. Finally, there has been a report of disagreement between information from the CMS Medical Evidence Report and Medicare physician claims for pre-ESRD care, suggesting the validity of data derived from one or both may be questionable (Kim, Desai, Chertow, \& Winkelmayer, 2012). However, the CMS Medical Evidence Report is the most comprehensive source of preESRD care data available at the present time.

\section{Implications for Nephrology Nurses}

Clinical (e.g. poor vasculature for AVF placement) and/or psychosocial (fear, trust, health beliefs) factors may underlie the less frequent receipt of composite preESRD care in younger and old elderly MHD patients. Given that nurses are frequently providers of pre-ESRD education, a nurse-led quality improvement initiative grounded in person, health, environment, and nursing might help to better engage these two groups of high-risk patients, as well as the entire community of pre-ESRD patients (Key, 2008; McEwen \& Wills, 2007). The nursing approach of assisting the individual with preESRD to attain balance through holistic, patient-centered care and education may help to ensure that composite pre-ESRD goals are met (Key, 2008).

Quality improvement initiatives in geriatric ESRD care have been successfully implemented and may ultimately improve care for elderly patients with ESRD (Tamura, 2009; Winkelmayer \& Tamura, 2012). Our findings of reduced pre-ESRD care should help to clarify some of the opportunities for pre-dialysis decision-making and 
management in the older elderly as well as younger MHD patients. Given our results, it is imperative that a more consistent approach to the provision of pre-ESRD care needs to be taken for this entire population. 


\section{References}

American Nephrology Nurses' Association. (2013). Vascular access for hemodialysis. Retrieved from: http://www.annanurse.org/download/reference/health/position/vascAccess.pdf Brick, N., \& Ellis, P. (2009). The significance of the timing of referral for renal care. Journal of Renal Care, 35, 33-41. doi: 10.1111/j.1755-6686.2009.00077.x

Chen, S. C., Chang, J. M., Chou, M. C., Lin, M. Y., Chen, J. H., Sun, J. H., , . Chen, H. C. (2008). Slowing renal function decline in chronic kidney disease patients after nephrology referral. Nephrology (Carlton), 13, 730-736. doi: 10.1111/j.14401797.2008.01023.x

Drawz, P. E., Babineau, D. C., \& Rahman, M. (2012). Metabolic complications in elderly adults with chronic kidney disease. Journal of American Geriatric Society, 60, 310-315. doi: $10.1111 / \mathrm{j} .1532-5415.2011 .03818 . \mathrm{x}$

Erdem, E., Prada, S. I., \& Haffer, S. C. (2013). Medicare payments: How much do chronic conditions matter? Medicare \& Medicaid Research Review, 3, E1-E15

Fayer, A.M., Nascimento, R., \& Abdulkader, R.C. (2011). Early nephrology care provided by the nephrologist alone is not suficient to mitigate the social and psychological aspects of chronic kidney disease. Clinical Science, 66, 245-250. doi: $10.1590 / \mathrm{S} 1807-59322011000200011$

Go, A. S., Chertow, G. M., Fan, D., McCulloch, C. E., \& Hsu, C. Y. (2004). Chronic kidney disease and the risks of death, cardiovascular events, and hospitalization. New England Journal of Medicine, 351, 1296-1305. doi: 10.1056/NEJMoa041031 
Gomes, A., Schmidt, R., \& Wish, J. (2013). Re-envisioning Fistula First in a patientcentered culture. Clinical Journal of the American Society of Nephrology, 8, 1791-1797. doi: 10.2215/cjn.03140313

Harford, R., Clark, M. J., Norris, K. C., \& Yan, G. (in press). Relationship between age and timely placement of vascular access in incident patients on hemodialysis. Nephrology Nursing Journal, 41, XXX-XXX.

Ismail, N., Neyra, R., \& Hakim, R. (1998). The medical and economical advantages of early referral of chronic renal failure patients to renal specialists. Nephrology Dialysis Transplantation, 13, 246-250.

Jones, C., Roderick, P., Harris, S., \& Rogerson, M. (2006). Decline in kidney function before and after nephrology referral and the effect on survival in moderate to advanced chronic kidney disease. Nephrology Dialysis Transplantation, 21, 21332143. doi: $10.1093 / \mathrm{ndt} / \mathrm{gfl} 198$

Key, S. M. (2008). Optimizing dialysis modality choices around the world: a review of literature concerning the role of enhanced early pre-ESRD education in choice of renal replacement therapy modality. Nephrology Nursing Journal, 35, 387-394; 395.

Kim, J. P., Desai, M., Chertow, G. M., \& Winkelmayer, W. C. (2012). Validation of reported predialysis nephrology care of older patients initiating dialysis. Journal of the American Society of Nephrology, 23, 1078-1085. doi:

10.1681/asn.2011080871

Tamura, M. (2009). Incidence, management, and outcomes of end-stage renal disease in the elderly. Current Opinion in Nephrology and Hypertension, 18, 252-257. 
Lee, J., Lee, J. P., Park, J. I., Hwang, J. H., Jang, H. M., Choi, J. Y., , . Lim, C. S. (2014). Early nephrology referral reduces the economic costs among patients who start renal replacement therapy: A prospective cohort study in Korea. PLoS One, 9, e99460. doi: 10.1371/journal.pone.0099460

Levey, A. S., Andreoli, S. P., DuBose, T., Provenzano, R., \& Collins, A. J. (2007). Chronic kidney disease: common, harmful and treatable-World Kidney Day 2007. American Journal of Nephrology, 27, 108-112.

Levey, A. S., Atkins, R., Coresh, J., Cohen, E. P., Collins, A. J., Eckardt, K. U., . . Eknoyan, G. (2007). Chronic kidney disease as a global public health problem: Approaches and initiatives - A position statement from Kidney Disease Improving Global Outcomes. Kidney International, 72, 247-259. doi: 10.1038/sj.ki.5002343

Lilly, M. P., Lynch, J. R., Wish, J. B., Huff, E. D., Chen, S. C., Armistead, N. C., \& McClellan, W. M. (2012). Prevalence of arteriovenous fistulas in incident hemodialysis patients: Correlation with patient factors that may be associated with maturation failure. American Journal of Kidney Disease, 59, 541-549. doi: 10.1053/j.ajkd.2011.11.038

McEwen, M., \& Wills, E. M. (2007). Theoretical Basis for Nursing. Philadelphia, PA: Lippincott Williams \& Wilkins.

Owen Jr, W. F., \& Norris, K. (1994). Nephrologists should be the primary care physician for minority, poor dialysis patients. Nephrology News \& Issues, 8(6), 54-55.

Prakash, S., Rodriguez, R. A., Austin, P. C., Saskin, R., Fernandez, A., Moist, L. M., \& O'Hare, A. M. (2010). Racial composition of residential areas associates with 
access to pre-ESRD nephology care. Journal of the American Society of Nephrology, 21, 1192-1199. doi: 10.1681/ASN.2009101008

Rastogi, A., Linden, A., \& Nissenson, A. R. (2008). Disease management in chronic kidney disease. Advances in Chronic Kidney Disease, 15(1), 19-28.

Rettig, R. A., Norris, K., \& Nissenson, A. R. (2008). Chronic kidney disease in the United States:A public policy imperative. Clinical Journal of the American Society of Nephrology, 3, 1902-1910. doi: 10.2215/CJN.02330508

Rettig, R., Vargas, R., Norris, K., \& Nissenson, A. R. (2010). A 'quiet revolution' in nephrology. Nephrology News Issues, 24(12), 18-19, 23.

Smart, N. A., Dieberg, G., Ladhani, M., \& Titus, T. (2014). Early referral to specialist nephrology services for preventing the progression to end-stage kidney disease. Cochrane Database of Systematic Reviews, 6, Cd007333. doi: 10.1002/14651858.CD007333.pub2

Stevens, P. E., \& Levin, A. (2013). Evaluation and management of chronic kidney disease: Synopsis of the kidney disease: Improving global outcomes 2012 clinical practice guideline. Annals of Internal Medicine, 158, 825-830. doi: 10.7326/00034819-158-11-201306040-00007

Stroupe, K. T., Fischer, M. J., Kaufman, J. S., O'Hare, A. M., Sohn, M. W., Browning, M. M., ... Hynes, D. M. (2011). Predialysis nephrology care and costs in elderly patients initiating dialysis. Medical Care, 49, 248-256. doi:

10.1097/MLR.0b013e31820192ba

Tamura, M. (2009). Incidence, management, and outcomes of end-stage renal disease in the elderly. Current Opinion in Nephrology and Hypertension, 18, 252-257. 
United States Renal Dialysis System. (2013). United States Renal Data System 2013 annual data report: Atlas of chronic kidney disease and end stage-renal disease in the United States. Bethesda, MD: National Institutes of Health

Vachharajani, T. J., Moist, L. M., Glickman, M. H., Vazquez, M. A., Polkinghorne, K. R., Lok, C. E., \& Lee, T. C. (2014). Elderly patients with CKD--Dilemmas in dialysis therapy and vascular access. Nature Reviews Nephrology, 10, 116-122. doi: $10.1038 /$ nrneph.2013.256

Winkelmayer, W. C., \& Tamura, M. K. (2012). Predialyis nephrology care of older individuals approaching end-stage renal disease. In Seminars in Dialysis, 25, 628632.

Yan, G., Norris, K. C., Yu, A. J., Ma, J. Z., Greene, T., Yu, W., Cheung, A. K. (2013). The relationship of age, race, and ethnicity with survival in dialysis patients. Clinical Journal of the American Society of Nephrology, 8, 953-61. doi: $10.2215 /$ CJN.09180912 
Table 1. Patient Characteristics by Age Group

\begin{tabular}{|c|c|c|c|c|}
\hline & $\begin{array}{c}<55 \text { years } \\
(\mathrm{n}=112,541)\end{array}$ & $\begin{array}{l}55-66 \text { years } \\
(\mathrm{n}=113,096) \\
\end{array}$ & $\begin{array}{l}67-79 \text { years } \\
(n=124,337)\end{array}$ & $\begin{array}{l}\geq 80 \text { years } \\
(\mathrm{n}=62,317)\end{array}$ \\
\hline Age (years), Mean $\pm \mathrm{SD}$ & $43.4 \pm 8.9$ & $60.7 \pm 3.4$ & $72.9 \pm 3.7$ & $84.1 \pm 3.4$ \\
\hline Male (\%) & 59.8 & 56.1 & 54.6 & 54.2 \\
\hline \multicolumn{5}{|l|}{ Race (\%) } \\
\hline Non-Hispanic white & 36.8 & 50.0 & 62.5 & 73.7 \\
\hline Non-Hispanic black & 40.8 & 30.9 & 22.5 & 15.4 \\
\hline Hispanic & 16.8 & 14.0 & 10.4 & 6.9 \\
\hline Other & 5.6 & 5.1 & 4.6 & 4.0 \\
\hline \multicolumn{5}{|l|}{ Insurance (\%) } \\
\hline No insurance & 19.2 & 8.7 & 1.0 & 0.5 \\
\hline Medicaid only & 24.1 & 14.5 & 2.2 & 1.2 \\
\hline Medicare only & 6.0 & 13.1 & 22.0 & 20.9 \\
\hline Other/combination & 50.7 & 63.7 & 74.8 & 77.4 \\
\hline Employed (\%) & 66.7 & 80.3 & 92.3 & 94.6 \\
\hline Hypertension (\%) & 83.7 & 85.5 & 85.6 & 85.1 \\
\hline Diabetes (\%) & 47.2 & 64.0 & 57.1 & 39.9 \\
\hline Congestive Heart Failure (\%) & 20.4 & 34.1 & 41.3 & 47.1 \\
\hline $\begin{array}{l}\text { Arteriosclerotic Heart Disease } \\
(\%)\end{array}$ & 9.2 & 22.1 & 30.8 & 34.3 \\
\hline Other Cardiac Disease (\%) & 8.7 & 15.7 & 21.4 & 25.5 \\
\hline $\begin{array}{l}\text { Cerebrovascular } \\
\text { accident/transient ischemic attack } \\
(\%)\end{array}$ & 5.5 & 10.4 & 12.5 & 12.6 \\
\hline Peripheral Vascular Disease (\%) & 8.0 & 15.3 & 19.0 & 18.1 \\
\hline Amputations (\%) & 3.5 & 4.4 & 2.9 & 1.4 \\
\hline $\begin{array}{l}\text { Chronic Obstructive Pulmonary } \\
\text { Disease (\%) }\end{array}$ & 3.9 & 9.8 & 13.4 & 12.7 \\
\hline Current smoker (\%) & 10.5 & 8.3 & 4.6 & 1.7 \\
\hline Cancer (\%) & 2.9 & 7.1 & 11.2 & 12.7 \\
\hline Inability to ambulate (\%) & 3.7 & 6.8 & 8.9 & 11.1 \\
\hline Inability to transfer (\%) & 1.5 & 3.1 & 4.5 & 5.9 \\
\hline $\begin{array}{l}\text { Needs assistance with daily } \\
\text { activities (\%) }\end{array}$ & 6.5 & 10.7 & 14.5 & 19.3 \\
\hline $\begin{array}{l}\text { Institutionalized - Nursing Home } \\
(\%)\end{array}$ & 2.6 & 5.5 & 8.8 & 13.2 \\
\hline
\end{tabular}


Table 2. Receipt of Pre-ESRD Care Elements, by Age Group

\begin{tabular}{|c|c|c|c|c|c|}
\hline & $\begin{array}{c}<55 \text { years } \\
(n=112,541)\end{array}$ & $\begin{array}{l}55-66 \text { years } \\
(n=113,096)\end{array}$ & $\begin{array}{l}67-79 \text { years } \\
(n=124,337)\end{array}$ & $\begin{array}{l}\geq 80 \text { years } \\
(n=62,317)\end{array}$ & $\begin{array}{c}\text { Total } \\
(\mathrm{N}= \\
412291)\end{array}$ \\
\hline $\begin{array}{l}\text { Receipt of } \\
\text { nephrologist care } \\
\text { at least } 12 \\
\text { months before } \\
\text { ESRD }(\%)\end{array}$ & 20.2 & 25.2 & 28.2 & 26.9 & 25.0 \\
\hline $\begin{array}{l}\text { Receipt of } \\
\text { dietitian care at } \\
\text { any time before } \\
\text { ESRD (\%) }\end{array}$ & 9.8 & 11.6 & 11.5 & 10.6 & 10.9 \\
\hline $\begin{array}{l}\text { AVF at first } \\
\text { dialysis (\%) }\end{array}$ & 12.7 & 15.2 & 15.5 & 13.0 & 14.3 \\
\hline $\begin{array}{l}\text { Mean number of } \\
\text { the three care } \\
\text { elements } \\
\text { received }\end{array}$ & 0.43 & 0.52 & 0.55 & 0.51 & 0.50 \\
\hline \multicolumn{6}{|l|}{$\begin{array}{l}\text { Percentage of the } \\
\text { three care } \\
\text { elements } \\
\text { received }(\%)\end{array}$} \\
\hline None & 68.4 & 62.4 & 59.8 & 62.4 & 63.3 \\
\hline 1 element & 21.9 & 25.3 & 27.2 & 26.1 & 25.0 \\
\hline 2 elements & 8.3 & 10.3 & 11.0 & 9.9 & 9.9 \\
\hline $\begin{array}{l}\text { All } 3 \\
\text { elements }\end{array}$ & 1.4 & 2.0 & 2.0 & 1.6 & 1.8 \\
\hline
\end{tabular}


Table 3. Unadjusted and Adjusted Ratios of the Mean Number of pre-ESRD Care

Elements Received for Respective Age Groups Compared with that In Reference Group

\begin{tabular}{|c|c|c|c|c|c|c|}
\hline $\begin{array}{l}\text { Age } \\
\text { Group }\end{array}$ & Ratio & $P$ value & Ratio & P value & Ratio & P value \\
\hline $\begin{array}{l}<55 \\
\text { years }\end{array}$ & \multicolumn{2}{|c|}{1 (reference) } & & & & \\
\hline $\begin{array}{l}55-66 \\
\text { years }\end{array}$ & $\begin{array}{c}1.21(1.20- \\
1.23)\end{array}$ & $<0.001$ & \multicolumn{2}{|c|}{1 (reference) } & & \\
\hline $\begin{array}{l}67-79 \\
\text { years }\end{array}$ & $\begin{array}{c}1.29(1.27- \\
1.30)\end{array}$ & $<0.001$ & $\begin{array}{c}1.06(1.05- \\
1.07)\end{array}$ & $<0.001$ & \multicolumn{2}{|c|}{1 (reference) } \\
\hline $\begin{array}{l}\geq 80 \\
\text { years }\end{array}$ & $\begin{array}{c}1.18(1.16- \\
1.20)\end{array}$ & $<0.001$ & $\begin{array}{c}0.97(0.96- \\
0.99)\end{array}$ & 0.001 & $\begin{array}{c}0.92 \\
(0.91- \\
0.93)\end{array}$ & $<0.001$ \\
\hline $\begin{array}{l}<55 \\
\text { years }\end{array}$ & \multicolumn{2}{|c|}{1 (reference) } & & & & \\
\hline $\begin{array}{l}55-66 \\
\text { years }\end{array}$ & $\begin{array}{c}1.09(1.07- \\
1.10)\end{array}$ & $<0.001$ & \multicolumn{2}{|c|}{1 (reference) } & & \\
\hline $\begin{array}{l}67-79 \\
\text { years }\end{array}$ & $\begin{array}{c}1.08(1.07- \\
1.10)\end{array}$ & $<0.001$ & $\begin{array}{c}0.99(0.98- \\
1.00)\end{array}$ & 0.239 & \multicolumn{2}{|c|}{1 (reference) } \\
\hline $\begin{array}{l}\geq 80 \\
\text { years }\end{array}$ & $\begin{array}{c}1.01(0.99- \\
1.03)\end{array}$ & $<0.180$ & $\begin{array}{c}0.93(0.92- \\
0.94)\end{array}$ & $<0.001$ & $\begin{array}{c}0.94 \\
(0.92- \\
0.95)\end{array}$ & $<0.001$ \\
\hline
\end{tabular}


Running head: REGIONAL VARIATIONS

\section{Chapter 4}

Manuscript 3

Regional Variations in the Interpretation of the ESRD Thirty-Month Coordination Period 


\section{Regional Variations in the Interpretation of the ESRD 30-Month Coordination}

\section{Period}

Ruby Harford, RN, MSN, PhD(c), Mary Jo Clark, PhD, RN, Guofen Yan, PhD, Keith C. Norris, MD, PhD

\section{Disclosure statement}

The authors declare that the manuscript has not been previously reported and is not under consideration for publication nor will be until a decision is made by the Nephrology Nursing Journal/Editor.

\section{Acknowledgements}

K.C.N is supported in part by NIH grant P20-MD000182, UL1TR000124, P30AG021684. G.Y is supported in part by NIH/NIDDK 5R01DK084200-04. The content is solely the responsibility of the authors and does not necessarily represent the official views of the National Institutes of Health.

\section{Author information and biographical statement}

Ruby Harford, RN, MSN, is a PhD candidate in the Hahn School of Nursing and Health Science at the University of San Diego, San Diego, CA, USA.

Mary Jo Clark, $\mathrm{PhD}, \mathrm{RN}$ is a Professor in the Hahn School of Nursing and Health Science at the University of San Diego, San Diego, CA, USA. 
Guofen Yan, $\mathrm{PhD}$, is a faculty biostatistician, School of Nursing and Department of Public Health Sciences, School of Medicine, University of Virginia, USA.

Keith $\mathrm{C}$. Norris, $\mathrm{MD}, \mathrm{PhD}$, is a senior faculty member, Division of General Internal Medicine and Health Services Research, David Geffen School of Medicine at University of California Los Angeles, CA, USA.

\section{Correspondence:}

Keith C. Norris, MD, PhD

Division of General Internal Medicine and Health Services Research

David Geffen School of Medicine, UCLA

911 Broxton Ave, Room 103

Los Angeles, CA 90024

310.794 .6973

310.794.0732-Fax

knorris@ucla.edu 


\begin{abstract}
Background and Objectives: Coordination of benefits (COB) between the Centers for Medicare \& Medicaid Services (CMS) national healthcare system and other healthcare insurance systems plays an important role in the determination of cost covered services for the end stage renal disease (ESRD) patient.
\end{abstract}

Methods: The study reviewed the 30 -month ESRD Coordination Period policy in the Territory of Puerto Rico over an 8-month period. The review included a search of regulatory documents and key stakeholder interviews with healthcare professionals, patients, and regulatory agencies in the Territory of Puerto Rico and the Centers for Medicaid \& Medicare Services regional office.

Findings: In the Territory of Puerto Rico, the ERSD coordination policy is three months based on a local 90 -day ESRD coordination period policy versus the national regulatory guidelines of 30 months. The variance interpretation of the ESRD COB has led to confusion among the payors, healthcare providers, the Medicare Administrative Contractor, and the patient in determining primary and secondary payor status for Medicare. This confusion has led, in turn, to delayed payments for health care delivery systems and duplication of copayments and out-of-pocket cost burden for patients.

Conclusions: A major effort is needed to harmonize the coordination period policy between the Territory of Puerto Rico and the national healthcare system to reduce undue burdens on providers and patients. 


\section{Introduction}

Chronic kidney disease (CKD) is a major source of premature morbidity affecting more than $10 \%$ of adults in the United States. Over 110,000 people each year develop end-stage renal disease (ESRD) requiring renal replacement therapy with either dialysis or renal transplantation (Centers for Disease Control and Prevention [CDC], 2014; National Institute of Diabetes and Digestive and Kidney Diseases [NIDDK], 2014). In 1972 , to address the growing disease burden, a special provision of the Social Security Act declared persons with ESRD who required renal replacement therapy to be disabled for purposes of Medicare Parts A and B. Medicare was established just seven years earlier in 1965 to support health care for the elderly and subsequently extended to disabled persons by Social Security Act amendments (Rettig, 2011). The ESRD Medicare program has now been in place for over 40 years.

At the level of the individual patient, the ESRD Medicare Secondary Payer provision or ESRD Coordination Period provides for a coordination of benefits period between Medicare and private health insurance plans for individuals entitled to Medicare solely on the basis of ESRD. If an individual is entitled to Medicare because of ESRD and is covered by an Employer Group Health Plan (EGHP), the EGHP is the first payer (primary) for the first 30 months (Centers for Medicare and Medicaid Services [CMS], 2013a). When first enacted in 1981, the period of coverage was 18 months, but was extended to 30 months in 1997 by the Balanced Budget Act (CMS, 2002). The regulation stipulates the EGHP is primary regardless of the number of employees and/or the Medicare beneficiary's employment status. This stipulation applies to all 50 states; the District of Columbia; the Commonwealth of Puerto Rico; the Virgin Islands; Guam; the 
Commonwealth of the Northern Mariana Islands; and American Samoa as well as the territorial waters adjoining the land areas of the United States for services provided onboard a ship (CMS, 2013b). The 30-month ESRD Coordination Period has been implemented in every region of the United States except of the territory of Puerto Rico (C. Hernandez, personal communication, May, 2014; First Coast Service Options Inc. 2014a). We undertook the present study to better understand the implications of differences in the interpretation and implementation of the Coordination Period policy in Puerto Rico.

\section{Methods}

We conducted a search of regulatory documents as well as key stakeholder interviews regarding the 30-month ESRD Coordination Period in the territory of Puerto Rico generated over an 8-month period. A synthesis of findings and implications for the way forward are presented here.

\section{Findings}

Many dialysis patients in Puerto Rico have other (EGHP) insurance, but the insurance covers only the first 90 days of dialysis treatments after the onset of ESRD. For such patients, Medicare is the primary payer for dialysis treatments during the standard ESRD beneficiary coordination period, which extends from the fourth through the $30^{\text {th }}$ month after onset of ESRD rather than after the $30^{\text {th }}$ month. In Puerto Rico, Medicare Secondary Payer (MSP) billing does not apply in such situations, as the health care insurers in Puerto Rico do not interpret the Medicare Coordination period to begin after 30 months. Typically, in other areas where the $30^{\text {th }}$ month rule is enforced, Medicare becomes the primary payer after the $30^{\text {th }}$ month coordination period. In Puerto Rico, 
however, Medicare is the secondary payer after the third month. The interpretation of Medicare's status as primary payer is believed to be supported by the Medicare regulations at 42 CFR $\S 411.161$ and $\S 411.162$ and by the guidelines at CMS 100-05 (MSP Manual) Chapter $1 \S 10.2$ and $\S 70.3$ and Chapter $3 \S 10.2$ (CMS, 2009, 2012a, 2012b; National Archives and Records Administration, 2014)). These interpretations have set forth the 90-day coordination period practiced in Puerto Rico to differ from the 30-month coordination period practiced elsewhere. This has important implications for dialysis care facilities, nephrologists, and the patients they care for.

The CMS claims system has no procedure to allow for Medicare as the primary payer for these beneficiaries who are within the $3^{\text {rd }}-30^{\text {th }}$ month ESRD period. Insurance companies and healthcare providers use the Common Working File (CWF) to obtain Medicare health insurance eligibility information. The CWF informs the claim system if the beneficiary is within the coordination period and if the individual has other insurance (e.g., EGHP). The aggregate insurance information and patient demographic data assist both Medicare and the healthcare provider in determining whether Medicare is the primary or secondary payer (CMS, 2013c, 2013d). The CWF does not include a data field that would identify the dialysis treatment as not covered by an active insurer and allow a Medicare primary payment. From our discussions, it is the position of intermediary insurers in Puerto Rico that dialysis treatment could be categorized as not covered by the insurer and that Medicare would then become the primary payer. They also voiced the perception that CMS has chosen not to invest in a system improvement that would directly address this situation.

First Coast Service Options Inc. (FCSO, 2014b), the Medicare Administrative 
Contractor (MAC) for Puerto Rico, uses a work-around in order to pay the claims for these beneficiaries. The work-around instructs dialysis facilities to enter occurrence code 24 and the "date of receipt of denial by higher priority payer" on the claim form. An occurrence code 24 is intended for use when it is believed that another insurer covers a service but the insurer denies payment (CMS-104, Chapter 8, § 50.3) (CMS, 2013e). It allows the contractor to make a conditional payment, that is, a payment governed by MSP billing procedures. Both FCSO and the Puerto Rico dialysis facilities understand that the payments are actually primary, not conditional payments, as does CMS.

FCSO requires dialysis facilities and nephrologists to actually bill the beneficiary's other insurer as if it were an MSP billing situation and assumes the insurer provides dialysis services as a cost-covered service as practiced on the U.S. mainland. Dialysis facilities and nephrologists do not submit the insurer denial with the claim; they are to retain it on file as documentation to confirm their entitlement to receive payment in case the claims are audited. This, unfortunately, can lead to the patient encountering additional out-of-pocket deductibles and additional bills related to the imposed insurer denial in this process. These bills are associated with the payer denying payment to the healthcare provider and then the healthcare provider may bill and pursue collection from the patient.

Although not intended by FCSO to create an onerous condition for dialysis facilities and nephrologists, the work-around procedure does so and, as noted above, also imposes an additional burden on patients. It requires dialysis facilities and nephrologists to expend resources to bill other insurers for services that they know the insurers do not cover so they can fill in a date for condition code 24 and file the record of denial. The 
insurers have no incentive to cooperate with the work-around process and may not respond to the claim or respond very late. At best, dialysis facility and nephrologists billing for Medicare eligible services are substantially delayed. At worst, providers' billing staff may lose track of some of the cases in the confusion resulting in a loss of revenue. If the standard Medicare claims system was revised so that it could recognize the claims at issue as payable by Medicare as primary payer, dialysis facilities and nephrologists would be entitled to bill immediately upon service and would be entitled to receive payment after the claims clear, as early as 14 days and no later than 29 days after claim submission. Claims not processed within that time would be payable with interest. Through no fault of their own, dialysis facilities and nephrologists do not receive these benefits.

In addition, some patients encounter partial coverage of care through two insurers (EGHP and Medicare) adding unnecessary co-payments and confusion around which insurer is the primary provider for other non-dialysis ESRD-related care. Confusion regarding cost-covered ESRD and non-ESRD services among the insurance agencies, patients, and the healthcare providers is a result of the common working file's inability to process the claims of the newly diagnosed ESRD Medicare beneficiaries residing in Puerto Rico. This can lead to patients overpaying, or, even worse, unintended missed payments to an insurer, which could be forwarded to a collection agency leading to a poor credit rating or even legal proceedings. CMS educational materials for ESRD patients cover insurance issues related to the 30 -month coordination period, but there are no materials or trainings for patients in Puerto Rico who must figure out on their own insurance issues based on a 90-day coordination period and any differences in 
apportionment of ESRD-related services.

\section{Recommendations}

The ideal solution is for the territory of Puerto Rico to adopt the 30-month ESRD coordination period. In lieu of that, one approach to a work-around at the provider level would be to revise how claims are processed in the common working file in a way that appropriately reduces the patient's, dialysis facilities', and nephrologists' administrative burdens as follows. The common working file should incorporate an exception or waiver that allows the billing of ESRD beneficiaries who reside in Puerto Rico to be processed after 90 days, rather than 30 months. That common working file is a system that is usually simple for FCSO to manage, protects the Medicare trust fund against improper payments, and meets CMS's timely and accurate payment objectives. When the Medicare beneficiary begins dialysis treatment, the provider would complete a questionnaire designed to determine whether Medicare is the primary or secondary payer. Puerto Rico beneficiaries typically have other insurance coverage, but not for dialysis services. According to the MSP manual, Chapter 3, $\S 10.1 .5 \mathrm{E}$ (CMS, 2012c), "If the information obtained does not indicate EGHP coverage, the provider annotates the bill to that effect (e.g., EGHP coverage lapsed, benefits exhausted)". That statement suggests that the Medicare claims system may actually have the flexibility to make primary payments for these claims without a major work-around, but merely adding the exception or waiver for Puerto Rico. If so, then the solution to dialysis facilities' and nephrologists' problem might already exist within standard billing procedures.

At a patient level, this would also help to address the additional insurance coverage gap. Many patients with a Medicare Prescription Drug Plan reach a point where 
their medication coverage runs out, known as the "donut hole". The traditional "donut hole" is due to a temporary limit on what a medication plan will cover. Patients in Puerto Rico not only face this issue, but also frequently face having to pay two deductibles for medications and other services due to having two insurers with unclear policies around attribution of coverage for costs as ESRD versus non-ESRD services and which insurer is responsible, creating a second "donut hole".

In summary, if the adoption of the 30-month ESRD coordination period is not feasible and a work-around were still necessary, we recommend a process in which the provider would not bill the EGHP, but would still enter a date with condition code 24 that would be pre-approved by CMS to allow the claim to be processed. Alternatively, if a date is not required in the notation field, a standard comment appropriate to the situation could be entered. Thus, the claim could be submitted without delay and processed without error.

Dialysis facilities and nephrologists would still have to obtain and keep adequate documentation of the beneficiary's lack of other insurance coverage for dialysis treatments during the ESRD coordination period. The documentation might consist of copies of the insurance contracts that show the benefits covered and any limitations. New copies of contracts could be obtained periodically to make sure there are no changes. If there are any further doubts, the insurer might be billed and issue an initial denial which could suffice throughout the remainder of the coordination period.

Effectively addressing the issue of a unique interpretation of the 30-month ESRD Coordination Period would be of significant benefit to both providers and patients. The proposed solutions represent potential strategies to more effectively address this issue. 
Again, a more complete solution would be to create a seamless and harmonized ESRD reimbursement system for the United States and all of its territories. 


\section{References}

Centers for Disease Control and Prevention. (2014). 2014 chronic disease national fact sheet. Retrieved from www.cdc.gov/diabetes/pubs/pdf/kidney-factsheets.pdf

Centers for Medicare and Medicaid Servivces Services. (2002). Medicare hospital manual: Transmittal 784. Retrieved from: http://www.cms.gov/Regulations-andGuidance/Guidance/Transmittals/downloads/R784HO.pdf

Centers for Medicare and Medicaid Services. (2009). Medicare secondary payor (MSP) manual: Chapter 2-MSP provisions. Retrieved from http://www.cms.gov/Regulations-andGuidance/Guidance/Manuals/Downloads/msp105c02.pdf

Centers for Medicare and Medicaid Services. (2012a). Medicare secondary payor (MSP): Chapter 1-Background and overview. Retrieved from https://www.cms.gov/Regulations-andGuidance/Guidance/Manuals/downloads/msp105c01.pdf Centers for Medicare and Medicaid. (2012b). Medicare secondary payor (MSP): Chapter 3-MSP provider physican and other billing supplier requirerments. Retrieved from http://www.cms.gov/Regulations-and-

Guidance/Guidance/Manuals/downloads/msp105c03.pdf

Centers for Medicare and Medicaid Services. (2012c). Medicare secondary payor (MSP) manual: Chapter 3 - MSP provider, physician, and other supplier and billing requirements. Retrieved from http://www.cms.gov/Regulations-andGuidance/Guidance/Manuals/downloads/msp105c03.pdf 
Centers for Medicare and Medicaid Services. (2013a). End stage renal disease.

Retrieved from http://www.cms.gov/Medicare/Coordination-of-Benefits-andRecovery/Coordination-of-Benefits-and-Recovery-Overview/End-Stage-RenalDisease-ESRD/ESRD.html

Centers for Medicare and Medicaid Services. (2013b). Medicare claims processing manual: Chapter 8-Outpatient ESRD hospital independent facility and physician supplier claims. Retrieved from https:/www.cms.gov/Regulations-andGuidance/Guidance/Manuals/downloads/clm104c08.pdf

Centers for Medicare and Medicaid Services. (2013c). Medicare claims processing manual: Chapter 27-Contractor instructions for CWF. Retrieved from http://www.cms.gov/Regulations-andGuidance/Guidance/Manuals/downloads/clm104c27.pdf

Centers for Medicare and Medicaid Services. (2013d). Medicare learning matters: Termination of the common working file ELGB provider query. Retrieved from http://www.cms.gov/Outreach-and-Education/Medicare-Learning-NetworkMLN/MLNMattersArticles/Downloads/mm8086.pdf

Centers for Medicare and Medicaid Services. (2013e). Medicare claims processing manual: Chapter 8-Outpatient ESRD hospital, independent facility and, physican supplier claims. Retrieved from https://www.cms.gov/Regulations-andGuidance/Guidance/Manuals/downloads/clm104c08.pdf

First Coast Service Options Inc. (2014a). Limitations on ESRD coverage by certain health care plans. Retreived from http://medicare.fcso.com/MSP/225672.asp 
First Coast Service Options Inc. (2014b). Conditional payment requests for MSP claims. Retrieved from http://medicare.fcso.com/MSP/210330.asp

National Archives and Records Administration, Office of the Federal Register. (2014). Electronic code of federal regulations. Retreived from http://www.ecfr.gov/cgibin/text-idx?c=ecfr\&tpl=/ecfrbrowse/Title42/42cfr411_main_02.tpl

National Institute of Diabetes and Digestive and Kidney Diseases. (2014). Kidney disease of diabetes. Retrieved from kidney.niddknih.gov/KUDiseases/pubs/kdd/index.aspx\#burden

Rettig, R.A. (2011). Special treatment -The story of Medicare's ESRD entitlement. New England Journal of Medicine, 364, 596-598. doi: 10.1056NEHMp1014193 


\section{Chapter Five}

\section{Summary and Discussion}

Two studies and a concept analysis were conducted addressing potential gaps in patient care management for chronic kidney disease. The reports included: Relationship between Age and Timely Placement of Vascular Access in Incident Patients on Hemodialysis, Relationship between Age and Pre-End Stage Renal Disease Care in Elderly Hemodialysis Patients, and Regional Variations in the Interpretation of the ESRD 30-Month Coordination Period. The studies were partitioned into two areas of chronic kidney disease (CKD) research: the analysis of age-related differences in the receipt of a composite of recommended care to include nephrologist and dietician care and use of an arteriovenous fistula at first outpatient dialysis. The concept analysis addressed regional variations in the interpretation of the end stage renal disease (ESRD) 30-month coordination period. This chapter will provide an overview of the findings, the significance to research, nursing practice, and health policy, and a proposed plan for future research based on the studies' findings and nursing implications. 


\section{Findings and Statistical Analysis of Manuscripts}

The first study Relationship Between Age and Timely Placement of Vascular Access in Incident Patients on Hemodialysis addressed the potential age related differences in use of a functioning arteriovenous fistula (AVF). The United States Renal Data System (USRDS), a national population based registry maintaining the largest dialysis data bank on almost all U.S. renal patients was used to extract dialysis data. The database houses and monitors characteristic profiles of renal-related disease groups, vulnerable populations, and communities with pre-end stage renal disease and kidney failure. For this study, the key variable was whether a patient used an AVF at the first outpatient hemodialysis therapy. Other study variables included demographic characteristics, employment status, health insurance coverage, and co-morbid conditions.

Four age groups were examined: $<55$ years of age, 55 to 66 years of age, 67 to 79 years of age, and $\geq 80$ years of age. Data were collected between the years 2005 through 2010. The study included all new maintenance hemodialysis (MHD) patients treated with renal replacement therapy (RRT) in any of the 50 states or the District of Columbia who were 18 years or older at the time of initiation of dialysis and entered in the USRDS. U.S. territories were excluded. A total of 559,056 individuals were reviewed: 153,611 (27.5\%) were younger than 55 years of age, $154,126(27.6 \%)$ were 55 to 66 years of age, $168,044(30 \%)$ were 67 to 79 years of age and 83,275 (14.9\%) were 80 years of age and older.

Logistic regression and descriptive analysis were used in the data analysis. Multiple analyses were conducted in adjusting for both unadjusted odds ratios with logistic regression, and then the odds ratios adjusted for other patient demographic data 
and characteristics. The study hypothesized that older patients were less likely to have a functioning AVF at the first dialysis treatment, however our findings showed the likelihood of using an AVF at first hemodialysis were lower for the youngest group and oldest groups (less than 55 years of age and 80 years and older).

In order to get a more comprehensive analysis of age related differences in the composite receipt of pre-ESRD care; a second study was conducted. Unlike the first study, this study increased the number of key study variables (pre-ESRD care elements) and was designed on a broader scale. The second study was an expansion of the first. Here we looked at a composite of three CMS recommended pre- ESRD care elements. In addition to the placement of a functioning AVF at the initial onset of incident hemodialysis care, the authors reviewed receipt of nephrologist care at least 12 months prior to receiving dialysis treatment and care by a dietician at any time prior to starting dialysis, resulting in a total of three pre-ESRD composite elements of care. Parallel to the first study, the USRDS database was used for data extraction. The same age groups were also used for comparative review. A sample of 412,291 individuals was examined. The study also hypothesized that older patients were less likely to receive the composite of CMS recommended pre-ESRD care elements than their younger counterparts.

The study used Poisson regression to evaluate findings. Poisson regression was used, which is most appropriate for frequency data, to compare four age categories ( $<55$ years of age, 55 to 66 years of age, 67 to 79 years of age, and $\geq 80$ years of age) expressed as ratios of the mean number of care elements received by respective age groups compared to that in the reference group (the 55-66 year group). The outcome variable was the composite of the three pre-ESRD care elements for MHD patients, 
measured as the total number of care elements received per patient (range: $0-3$ ). Multiple analyses were conducted to evaluate for both adjusted and unadjusted ratios using patient characteristics and demographics, and other study variables. Consistent with the first study, the key findings revealed the receipt of recommended elements of care was lowest in the youngest ( $<55$ years of age) and oldest groups $(\geq 80$ years of age) when compared to the two groups in between. In addition to the above findings, the analysis revealed overall pre-ESRD care was extremely low. Less than $2 \%$ of the MHD population was reported to have received all three elements of recommended care. The actual receipt of care was $1.4 \%$.

The concept analysis examined regional variations in the interpretation of the ESRD 30-month Coordination Period. Over an 8-month period, the authors conducted a search of regulatory documents as well as key stakeholder interviews regarding coordination of benefits for the ESRD patient. The findings revealed discordance in the interpretation and implementation of ESRD cost covered services between the Territory of Puerto Rico and the national ESRD insurance program. Many dialysis patients in Puerto Rico have employee group healthcare plans (EGHP), which cover dialysis services up to 90 days after the onset of ESRD (First Coast Services Options Inc. [FCOS], 2014; Centers for Medicaid and Medicare Services [CMS], 2014). Based on the ESRD coordination period in Puerto Rico, after the 90-day period Medicare becomes the primary payer for dialysis treatments. This finding is contrary to the federal regulatory guidelines and practice in other states and territories where the ESRD Coordination Period is 30 months and not limited to 90 days after the onset of kidney failure (Code of Federal Regulations, 2011; CMS, 2013). It is important to note the national framework 
for processing ESRD audit and reimbursement claims processing is structured to coordinate ESRD claims processing on a 30-month coordination period, not 90 days.

The current system does not allow for a seamless payer transition for Medicare as the primary payer for ESRD patients residing in Puerto Rico after the 90-day coordination period. Consequently, this has created confusion among the payers, healthcare providers, and the patients in determining who are the primary and secondary payers. In addition, the extra work necessary to process the claims management and handing has resulted in an increase billing cost.

\section{Research Questions and Hypothesis Findings}

The conducted studies answered four questions central to the receipt of preESRD composite care elements and policy variations on the 30-month Coordination Period policy for ESRD patients in the Territory of Puerto Rico. The first three questions examined the receipt of pre-ESRD composite care elements and were answered by the first two studies:

1. Is there a difference in rate of placement of an AVF prior to initiation of hemodialysis between persons aged $\geq 67$ years of age and those $<67$ years of age?

2. Is there a difference in the rate of receipt of early nephrology care prior to initiation of hemodialysis between persons aged $\geq 67$ years of age and those $<67$ years of age?

3. Is there a difference in the rate of receipt of dietary care prior to initiation of hemodialysis between persons aged $\geq 67$ years of age and those $<67$ years of age? 
As discussed earlier, our combined study findings revealed a low rate on the receipt of the three composite pre-ESRD care elements overall. These findings were consistent with the first study on AVF placement prior to the initiation of initial dialysis. In addition, the study hypothesized that persons aged $\geq 67$ years received a lower level of quality of care than younger persons $<67$ years of age, however our findings indicated that both the younger and older age groups experienced a lower quality on the receipt of pre-ESRD care elements and not just the older age group as initially hypothesized.

The last question examined regional variances in the ESRD 30-month Coordination Period policy and was addressed in the policy analysis:

1. Is there a difference in the interpretation and implementation of the Coordination Period policy in Puerto Rico?

Our search on regional variance on the interpretation of the ESRD 30-month Coordination Period policy identified Puerto Rico as practicing a different ESRD coordination policy. While other territories and states work under a 30-month coordination period, Puerto Rico operates under a 90-day system. As discussed earlier, this variation in practice creates a complex processing system for ESRD claims resulting in higher billing costs and greater out-of-pocket expenses for patients, as well as confusion among the healthcare providers, payors and patients in determining order of payors.

\section{Discussion}

To our knowledge, these studies are the first of their kind examining age-related differences in the use of an AVF at the initial dialysis treatment along with the receipt of nephrology and dietician care prior to the start of dialysis care. Our findings are 
consistent with earlier research indicating older patients as having lowest rate of AVF placement at initial treatment along with other pre-ESRD care elements (Lilly et al., 2012, Kim; Dessai, Chertow, \& Winkelmayer, 2012). Work conducted by Gomes, Schmidt, \& Wish (2013) discussed the clinical and pre-ESRD care challenges for those patients who may not be good candidates for AVF placement in addition to overall low rates of early CKD care in general. A thematic finding on pre-ESRD care studies is early nephrology care continues to be consistently low if not absent. Our findings were consistent with these studies.

The promotion of universal healthcare insurance coverage for pre-ESRD services across all age groups is needed to slow down the national burden of kidney disease. As noted in the regional variances of the ESRD coordination policy in Puerto Rico, confusion on cost covered services may lead to patients not seeking appropriate care for fear of high out-of-pocket expense. In addition, this confusion may also lead to healthcare providers not admitting new CKD patients for fear of non-payment. A re-examination of the national claims processing system is warranted based on Puerto Rico's ESRD coordination policy. A more harmonized management of the overall billing and claims system may assist in simplifying the claims processing for Puerto Rico, the Medicare Administrative Contractor, and the national healthcare insurance program.

\section{Implications}

The summative findings of the three studies should be a reminder to all nephrology nurses as members of the pre-ESRD and ESRD multidisciplinary care team; nurses can make a difference at various levels of the healthcare spectrum. From policy development, research, and clinical practice, nurses have the opportunity to be at the 
forefront in the patient care and chronic disease management for the pre-ESRD and ESRD patient.

\section{Significance to Research}

Based on the study's findings, immediate action is needed to implement a more comprehensive pre-ESRD patient care program and monitor its impact on the delivery of all three pre-ESRD care elements. Monitoring patient outcomes after initiation of renal replacement therapy may lead to improved early management of CKD and improved preESRD and ESRD healthcare economics. Two key factors contributing to the increasing prevalence of CKD are an aging population and the leading CKD risk factors, diabetes and hypertension (Erdem, Prada, \& Haffer 2013). Nurse researchers are strategically poised to assist in ESRD policy revision and innovative changes influencing the preventive and long-term management of chronic disease particularly with the aged ESRD patient. Collaborative partnerships with other professional healthcare agencies supporting kidney disease care platforms provide greater funding opportunities for renal research.

The first two studies described here specifically excluded data related to patients in the U.S. territories and protectorates. Similar research on the extent of pre-ESRD care and age-related discrepancies are warranted for those populations.

\section{Significance to Nursing Practice}

Currently national certification for the advanced nephrology nurse practitioner does not exist. The opportunity to develop a more expanded role for a nationally certified Advanced Nephrology Nurse Practitioner may help in the long-term care of both the preESRD and ESRD patient. Gaps in the literature review support the need for new and 
innovative initiatives expanding the role for the renal nurse generalist, advanced nurse practitioner, and the renal patient care team (Davis \& Zuber, 2013). The development of an advanced nephrology renal practitioner role may help to fill this void.

\section{Significance for Health Policy}

Clinical and/or psychosocial factors may underscore the less frequent receipt of pre-ESRD composite care in the older and younger kidney disease populations. Given that nurses are frequently providers of pre-ESRD education, a nurse-led quality improvement initiative grounded in person, health, environment, and nursing might help to better engage these two groups of high-risk patients, as well as the entire community of pre-ESRD patients (Key, 2008; McEwen \& Wills, 2007). The nursing approach of assisting the individual with pre-ESRD to attain balance through holistic, patient-centered care and education may also assist to ensure that composite pre-ESRD goals are met (Key, 2008).

Quality improvement initiatives in geriatric ESRD care have been successfully implemented and may ultimately improve care for elderly patients with ESRD (Tamura, 2009; Winkelmayer \& Tamura, 2012). Our findings of reduced pre-ESRD care should help to clarify some of the opportunities for pre-dialysis decision-making and management in the older as well as younger MHD patients. Given our results, it is imperative that a more consistent approach to the provision of pre-ESRD care needs to be taken for this entire population.

At its most granular level, the nursing profession is patient-centric. This makes nurses unique in their ability to work one on one with both patient and family. More importantly, it positions them as strong patient advocates and clinicians. The confluence 
of these attributes places nurses at the leadership helm to assist in policy revision, development, and implementation.

\section{Proposed Plan}

The research assisted in further identifying gaps in the care of the dialysis patient population at a federal and territorial level, all of which influence renal disease management, nursing practice, and ultimately ESRD healthcare policy. In order to clearly understand next steps in the furtherance of the study, study limitations have been addressed. Study limitations include the cross sectional nature of the data that only allowed the team to assess relationships and not causal affects. In addition, prior reports have suggested the validity of the shared information from the CMS Medical Evidence Report and Medicare physician claims for pre-ESRD care is not clear, indicating a need for a more in-depth review of the data utilization and data management at a more germane level (Kim et al., 2012). The team plans to further investigate the utilization of other integrated healthcare and population census databases, which may help to improve the validity of the current database and provide opportunities for expansion into other research platforms. Adding a secondary database may strengthen future studies.

Finally, the research team has proposed that future studies are needed at the territorial level to obtain a better understanding of possible patient care gaps and potential economic effects at the federal and local level. Because the demand for dialysis care continues to grow, there is an urgent need for more studies in the renal area relating to policy and nursing practice. This study provided a platform for future territorial studies and in other areas with similar populations (e.g., rural settings). 


\section{References}

Centers for Medicaid \& Medicare Services. (2013). End stage renal disease. Retrieved from http://www.cms.gov/Medicare/Coordination-of-Benefits-andRecovery/Coordination-of-Benefits-and-Recovery-Overview/End-Stage-RenalDisease-ESRD/ESRD.html

Centers for Medicaid \& Medicare Services. (2014). Medicare as secondary payer.

Retrieved from http://www.cms.gov/Medicare/Coordination-of-Benefits-andRecovery/Coordination-of-Benefits-and-Recovery-Overview/MedicareSecondary-Payer/Downloads/MSP-End-Stage-Renal-Disease-ESRD.pdf Code of federal regulations. (2011). Code of federal regulations. Retrieved from:

http://www.gpo.gov/fdsys/pkg/CFR-2011-title42-vol2/xml/CFR-2011-title42vol2-sec411-163.xml

Davis, J. S., \& Zuber, K. (2013). Implementing patient education in the CKD clinic. Advances in Chronic Kidney Disease, 20, 320-325. doi:10.1053/j.ackd.2013.04.004

Erdem, E., Prada, S. I., \& Haffer, S. C. (2013). Medicare payments: How much do chronic conditions matter? Medicare \& Medicaid Research Review, 3, E1-E15.

First Coast Service Options Inc. (2014). Limitations on ESRD coverage by certain health care plans. Retreived from http://medicare.fcso.com/MSP/225672.asp

Gomes, A., Schmidt, R., \& Wish, J. (2013). Re-envisioning Fistula First in a patient centered culture. Clinical Journal of the American Society of Nephrology, 8, 1791-1791. doi: $10.2215 /$ cjn.03140313 
Key, S. M. (2008). Optimizing dialysis modality choices around the world: A review of literature concerning the role of enhanced early pre-ESRD education in choice of renal replacement therapy modality. Nephrology Nursing Journal, 35, 387-394; 395.

Kim, J. P., Desai, M., Chertow, G. M., \& Winkelmayer, W. C. (2012). Validation of reported predialysis nephrology care of older patients initiating dialysis. Journal of American Society of Nephrology, 23, 1078-1085. doi:

10.1681/asn.2011080871

Lilly, M. P., Lynch, J. R., Wish, J. B., Huff, E. D., Chen, S. C., Armistead, N. C., \& McClellan, W. M. (2012). Prevalence of arteriovenous fistulas in incident hemodialysis patients: Correlation with patient factors that may be associated with maturation failure. American Journal of Kidney Disease, 59, 541-549. doi: 10.1053/j.ajkd.2011.11.038

McEwen, M., \& Wills, E. M. (2007). Theoretcial basis for nursing. Philadelphia, PA: Lippincott Williams \& Wilkins.

Tamura, M. K. (2009). Incidence, management, and outcomes of end-stage renal disease in the elderly. Current Opinion in Nephrology and Hypertension, 18, 252-257.

Winkelmayer, W. C., \& Tamura, M. K. (2012). Predialyis nephrology care of older individuals approaching end-stage renal disease. In Seminars in Dialysis, 25, 628632. doi: $10.1111 /$ sdi. 12036 